\title{
Atmospheric degradation of 3-methylfuran: kinetic and products study
}

\author{
A. Tapia ${ }^{1}$, F. Villanueva ${ }^{1,2}$, M. S. Salgado ${ }^{3}$, B. Cabañas ${ }^{3}$, E. Martínez ${ }^{3}$, and P. Martín ${ }^{3}$ \\ ${ }^{1}$ Instituto de Tecnologías Química y Medioambiental (ITQUIMA), Laboratorio de Contaminación Atmosférica, Universidad \\ de Castilla La Mancha, Avda Camilo José Cela s/n, 13071, Ciudad Real, Spain \\ ${ }^{2}$ Parque Científico y Tecnológico de Albacete, Paseo de la Innovación 1, 02006 Albacete, Spain \\ ${ }^{3}$ Departamento de Química Física, Facultad de Ciencias Químicas, Universidad de Castilla La Mancha, Avda Camilo José \\ Cela s/n, 13071 Ciudad Real, Spain
}

Received: 30 August 2010 - Published in Atmos. Chem. Phys. Discuss.: 5 October 2010

Revised: 22 February 2011 - Accepted: 26 February 2011 - Published: 5 April 2011

\begin{abstract}
A study of the kinetics and products obtained from the reactions of 3-methylfuran with the main atmospheric oxidants has been performed. The rate coefficients for the gas-phase reaction of 3-methylfuran with $\mathrm{OH}$ and $\mathrm{NO}_{3}$ radicals have been determined at room temperature and atmospheric pressure (air and $\mathrm{N}_{2}$ as bath gases), using a relative method with different experimental techniques. The rate coefficients obtained for these reactions were (in units $\mathrm{cm}^{3}$ molecule $\left.\mathrm{s}^{-1}\right) k_{\mathrm{OH}}=(1.13 \pm 0.22) \times 10^{-10}$ and $k_{\mathrm{NO}_{3}}=(1.26 \pm 0.18) \times 10^{-11}$. Products from the reaction of 3-methylfuran with $\mathrm{OH}, \mathrm{NO}_{3}$ and $\mathrm{Cl}$ atoms in the absence and in the presence of NO have also been determined. The main reaction products obtained were chlorinated methylfuranones and hydroxy-methylfuranones in the reaction of 3methylfuran with $\mathrm{Cl}$ atoms, 2-methylbutenedial, 3-methyl2,5-furanodione and hydroxy-methylfuranones in the reaction of 3-methylfuran with $\mathrm{OH}$ and $\mathrm{NO}_{3}$ radicals and also nitrated compounds in the reaction with $\mathrm{NO}_{3}$ radicals. The results indicate that, in all cases, the main reaction path is the addition to the double bond of the aromatic ring followed by ring opening in the case of $\mathrm{OH}$ and $\mathrm{NO}_{3}$ radicals. The formation of 3-furaldehyde and hydroxy-methylfuranones (in the reactions of 3-methylfuran with $\mathrm{Cl}$ atoms and $\mathrm{NO}_{3}$ radicals) confirmed the $\mathrm{H}$-atom abstraction from the methyl group and from the aromatic ring, respectively. This study represents the first product determination for $\mathrm{Cl}$ atoms and $\mathrm{NO}_{3}$ radicals in reactions with 3-methylfuran. The reaction mechanisms and atmospheric implications of the reactions under consideration are also discussed.
\end{abstract}

Correspondence to: P. Martín (mariapilar.martin@uclm.es)

\section{Introduction}

3-Methylfuran is a furan derivative that is released into the atmosphere during the combustion of fossil fuels, waste, biomass and from isoprene degradation (Graedel et al., 1986; Andreae and Merlet, 2001). In ambient air, 3-methylfuran has been measured above a rural forested site with mean daytime mixing ratios estimated at $60 \mathrm{ppt}$ and nighttime levels of 40 ppt (Montzka et al., 1995).

The mixing ratios of 3-methylfuran were highly correlated with isoprene (Atkinson et al., 1984; Gu et al., 1995; Lee et al., 2005), which is the most abundant biogenic hydrocarbon emitted into the atmosphere with a global emission rate between 250 and $500 \mathrm{Tg} \mathrm{yr}^{-1}$, exceeding that of anthropogenic hydrocarbons (Guenther et al., 2006; Laothawornkitkul et al., 2009). The reaction of isoprene with $\mathrm{OH}$ gives 3-methylfuran in an approximate yield of 3-7\% depending presumably on the pressure (Ruppert and Becker, 2000; Lee et al., 2005). Therefore, and due to the high emission rates of isoprene, the potential atmospheric significance of the oxidation products (3-methylfuran) increases.

3-Methylfuran is expected to be very reactive with the main atmospheric oxidants. According to Atkinson et al. (1989), 3-methylfuran may play a role, albeit minor, in the chemical cycles in the lower troposphere. To date few kinetic studies have been published concerning 3-methylfuran. Indeed, only one value has been reported for the rate coefficient at room temperature for the reaction of the $\mathrm{OH}$ radical with 3-methylfuran and this was obtained using a relative technique (Atkinson et al., 1989). Furthermore, two kinetic studies on the reaction of 3-methylfuran with the $\mathrm{NO}_{3}$ radical have been published (Kind et al., 1996; Alvarado et al., 1996) and these gave two very different values for the rate

Published by Copernicus Publications on behalf of the European Geosciences Union. 
coefficient. In the case of the reaction with $\mathrm{Cl}$ atoms, the rate coefficient reported in the literature was obtained by Cabañas et al. (2005).

With regard to the reaction products, the data available in the literature are particularly scarce. A recent product study on the photooxidation of 3-methylfuran with HONO indicates that 2-methylbutenedial is the main gaseous product of the OH-oxidation of this compound (Gómez Álvarez et al., 2009). A theoretical computational study has also been published for this reaction and the conclusion was that direct hydrogen abstraction and nucleophilic bimolecular substitution play a minor or negligible role in the overall reaction (Zhang et al., 2008).

In the work described here the rate coefficients for the reaction of $\mathrm{OH}$ and $\mathrm{NO}_{3}$ radicals with 3-methylfuran were determined in order to (i) assess the values previously reported in the literature as some discrepancies are apparent and (ii) to complete the kinetic study of alkylfurans initiated by our research group. Experiments were carried out at $(298 \pm 2) \mathrm{K}$ and a total pressure of $1 \mathrm{~atm}$ using a relative rate method with LOOP/SPME-GC/FID/MS (Loop/Solid Phase Microextraction-Gas Chromatography/Flame Ionization Detection/Mass Spectrometry Detection) and FTIR (Fourier Transform Infrared Spectroscopy) as detection techniques for the organic compounds.

Products obtained in the reaction of 3-methylfuran with $\mathrm{OH}$ and $\mathrm{NO}_{3}$ radicals and with $\mathrm{Cl}$ atoms were also characterised in order to propose degradation mechanisms for this compound in the atmosphere. This reaction product study was carried out using SPME-GC/FID/MS and FTIR as detection methods.

\section{Experimental section}

\subsection{Kinetic study}

Rate coefficients for the gas phase reactions of 3-methylfuran with the atmospheric oxidants, $\mathrm{OH}$ and $\mathrm{NO}_{3}$ radicals, at $(298 \pm 2) \mathrm{K}$ and $\sim 1 \mathrm{~atm}$ of the total pressure in synthetic air and $\mathrm{N}_{2}$, respectively, were determined using a relative rate method. The reactions of 3-methylfuran and reference compounds (with rate coefficients $k_{\mathrm{S}}$ and $k_{\mathrm{R}}$, respectively) were monitored in the presence of $\mathrm{OH}$ or $\mathrm{NO}_{3}$ radicals:

$\mathrm{X}+$ Substrate $(\mathrm{S}) \rightarrow$ products $\left(k_{\mathrm{S}}\right)$

$\mathrm{X}+$ Reference compound $(\mathrm{R}) \rightarrow$ products $\left(k_{\mathrm{R}}\right)$

where $\mathrm{X}$ is $\mathrm{OH}$ or $\mathrm{NO}_{3}$

As described in detail elsewhere (Atkinson et al., 1982) the decay of the substrate from $[\mathrm{S}]_{0}$ at time $t=0$ to $[\mathrm{S}]_{t}$ at time $t$ and the simultaneous loss of the reference compound from an initial concentration of $[\mathrm{R}]_{0}$ to $[\mathrm{R}]_{t}$ at time $t$ is given by Eq. (1):

$\ln \left(\frac{[S]_{0}}{[S]_{t}}\right)=\frac{k_{\mathrm{S}}}{k_{\mathrm{R}}} \ln \left(\frac{[R]_{0}}{[R]_{t}}\right)$
Thus, a plot of $\ln \left([\mathrm{S}]_{0} /[\mathrm{S}]_{t}\right)$ versus $\ln \left([\mathrm{R}]_{0} /[\mathrm{R}]_{t}\right)$ should be a straight line passing through the origin and the slope should give the ratio of rate coefficients $k_{\mathrm{S}} / k_{\mathrm{R}}$. Each reaction studied was measured relative to the reaction of different reference standards with oxidants X. In the case of 3-methylfuran with $\mathrm{NO}_{3}$, a dilution term was included in Eq. (1) due to the special experimental procedure, which is described below. Therefore, for this reaction the equation required to obtain the rate coefficient is:

$\ln \left(\frac{[S]_{0}}{[S]_{t}}\right)-D_{t}=\frac{k_{\mathrm{S}}}{k_{\mathrm{R}}}\left(\ln \frac{[R]_{0}}{[R]_{t}}-D_{t}\right)$

where $D_{t}$ is calculated as $D_{t}=\ln \left([\mathrm{I}]_{0} /[\mathrm{I}]_{t}\right)$ and $I$ is an internal standard.

The relative rate technique relies on the assumption that both the substrate and the reference compound are removed solely by the reaction with $\mathrm{OH}$ or $\mathrm{NO}_{3}$ radicals. In an effort to verify this assumption, various tests were performed to assess the loss of 3-methylfuran by reaction with precursors of $\mathrm{OH}$ and $\mathrm{NO}_{3}$ radicals, photolysis and wall deposition. These processes, which could interfere with the kinetic determinations, were found to be negligible for 3-methylfuran and the selected reference compounds.

The experimental systems and the procedures used in this work are briefly described below. Further details can be found elsewhere (Cabañas et al., 2005; Villanueva et al., 2007, 2009). Only the FTIR system with a 50 L Pyrex glass vessel is described below in detail.

Three analytical systems were used in the experiments: gas chromatography with flame ionization detection (GC/FID), gas chromatography with mass spectrometry detection (GC/MS) and Fourier transform infrared absorption spectroscopy (FTIR). In the kinetic experiments carried out with gas chromatography, two evacuable Teflon-coated bags (Adtech) were used - one with a volume of $150 \mathrm{~L}$ for the experiments with $\mathrm{OH}$ radicals and one $500 \mathrm{~L}$ bag for the experiments with $\mathrm{NO}_{3}$ in order to minimize the dilution effect of the additions of $\mathrm{N}_{2} \mathrm{O}_{5}$. These bags were placed inside a rectangular cage with six VIS lamps $\left(\lambda_{\max }=360 \mathrm{~nm}\right)$ mounted on the walls. The sampling methods included a system based on sample preconcentration, the solid phase microextraction technique (SPME) and a heated loop with a capacity of $1 \mathrm{~cm}^{3}$ mounted in a six way valve. In the first case, the samples were collected for $15 \mathrm{~min}$ by exposing a $50 / 30 \mathrm{~mm}$ DVB/CAR/PDMS fibre to the reaction mixture in the Teflon bag. The fibre was then thermally desorbed for $10 \mathrm{~min}$ at $270^{\circ} \mathrm{C}$ in the heated $\mathrm{GC}$ injection port. In the second case, the reaction mixture was slowly pumped through the sampling loop to ensure that it was thoroughly flushed and then allowed to come to equilibrium with a reaction chamber pressure of $1 \mathrm{~atm}$ prior to injection. The concentrations of 3-methylfuran and the reference compounds were followed by capillary gas chromatography and detection by FID or MS. In all the experiments a capillary column $(30 \mathrm{~m} \times 0.3 \mathrm{~mm}$ id $\times 1.0 \mu \mathrm{m}$ film thickness, Tracsil 
TRB-1701, Teknokroma) was used to separate the compounds. The chromatographic conditions used for the analysis were as follows: injector $270^{\circ} \mathrm{C}$; detector $250^{\circ} \mathrm{C}$; temperature programme from $40^{\circ} \mathrm{C}(4 \mathrm{~min})$ to $120^{\circ} \mathrm{C}(17 \mathrm{~min})$ at a rate of $25^{\circ} \mathrm{C} \mathrm{min}^{-1}$.

The in situ FTIR analysis of 3-methylfuran with $\mathrm{OH}$ and $\mathrm{NO}_{3}$ radicals was carried out in a $50 \mathrm{~L}$ Pyrex glass reaction chamber at a total pressure of approximately $1 \mathrm{~atm}$ and $(298 \pm 2) \mathrm{K}$ in synthetic air. The reactants were injected into the reaction chamber using a vacuum line. A pumping system consisting of a rotary pump (Varian DS 302) was used to evacuate the reactor after every experiment. The photolysis system consisted of eight actinic fluorescent lamps $\left(\lambda_{\max }=360 \mathrm{~nm}\right)$ spaced evenly around the reaction chamber. The chamber was equipped with a White-type multiple-reflection mirror system (Saturn Series Multi-Pass cells) with a base length of $1.35 \mathrm{~m}$ for sensitive in situ long path absorption monitoring of reactants and products in the IR spectral range $4000-650 \mathrm{~cm}^{-1}$. The White system can operate at 72 traverses, giving a total optical path length of $200 \mathrm{~m}$. The IR spectra were recorded with a resolution of $1 \mathrm{~cm}^{-1}$ using a Thermo Nicolet 5700 FT-IR spectrophotometer equipped with a $\mathrm{KBr}$ beam splitter and a liquid nitrogen cooled mercury-cadmium-telluride (MCT) detector. Typically, for each spectrum, 60 interferograms were co-added over $2 \mathrm{~min}$ and approximately 30 such spectra were recorded per experiment.

The techniques and the reference compounds used in the reactions of 3-methylfuran with $\mathrm{OH}$ and $\mathrm{NO}_{3}$ radicals are listed in Table 1.

In the experiments performed with LOOP/GC-MS, benzene was used as the internal standard. The reactant mixtures were photolysed for $0.5-2.0 \mathrm{~min}$ and a gas chromatogram or an IR spectrum of the chamber contents was recorded. This photolysis-sampling procedure was repeated until about 54$93 \%$ depletion of the 3-methylfuran and $41-83 \%$ depletion of the reference compound were achieved. Typically six to seventeen photolysis-sampling steps were carried out during each experiment. Hydroxyl radicals were generated in the presence of $\mathrm{NO}$ by the photolysis of $\mathrm{CH}_{3} \mathrm{ONO}$ (Atkinson et al., 1982) in air at a wavelength of $360 \mathrm{~nm}$ using the VIS lamps.

Nitrate radicals were generated in situ in the dark by the thermal decomposition of $\mathrm{N}_{2} \mathrm{O}_{5}$ (Atkinson et al., 1984). During GC-FID experiments successive additions of $\mathrm{N}_{2} \mathrm{O}_{5}\left(2.5 \times 10^{13}-1.1 \times 10^{14}\right.$ molecule $\left.\mathrm{cm}^{-3}\right)$ were performed. Sampling was carried out approximately $7 \mathrm{~min}$ after the addition of $\mathrm{N}_{2} \mathrm{O}_{5}$ and at subsequent intervals of $18 \mathrm{~min}$. A total of nine additions were typically made in each experiment. This procedure led to a depletion for 3methylfuran of $81 \%$ and a depletion for the reference compound of $72 \%$. In FTIR experiments only one addition of $\mathrm{N}_{2} \mathrm{O}_{5}$ at $\left(1.1 \times 10^{15}\right)$ molecule $\mathrm{cm}^{-3}$ was performed. This procedure led to a depletion for 3-methylfuran of 58-100\% and a depletion for the reference compound of $59-96 \%$.
The initial reactant concentrations in the reactors (in molecule $\left.\mathrm{cm}^{-3}\right)$ were as follows: [3-methylfuran] $=(2-$ $9) \times 10^{14}$, [reference $]=(1.5-9) \times 10^{14},\left[\mathrm{CH}_{3} \mathrm{ONO}\right]=(3-$ $15) \times 10^{14},[\mathrm{NO}]=(2-28) \times 10^{14}$ and [benzene $]=(4-$ 15) $\times 10^{14}$.

\subsection{Products study}

Product experiments were carried out at $(298 \pm 2) \mathrm{K}$ with air at atmospheric pressure in different reaction chambers: (a) in a $150 \mathrm{~L}$ evacuable Teflon-coated chamber equipped with six $360 \mathrm{~nm}$ lamps and four $254 \mathrm{~nm}$ lamps and with the provision for sampling onto a 30/50 $\mu \mathrm{m}$ SPME (DVB/CAR/PDMS) fibre. The fibre adsorption and desorption time was $15 \mathrm{~min}$ at $270^{\circ} \mathrm{C}$ in split/splitless mode for the GC injection port. The analysis in this case was carried out by GC/MS and GC/FID. Products were separated in the capillary column by applying the following temperature programme: from $40^{\circ} \mathrm{C}(4 \mathrm{~min})$ to $120^{\circ} \mathrm{C}(12 \mathrm{~min})$ at a rate of $25^{\circ} \mathrm{C} \mathrm{min}-1$, then at a rate of $10^{\circ} \mathrm{C} \mathrm{min}^{-1}$ up to $200^{\circ} \mathrm{C}(10 \mathrm{~min})$. Mass spectrometry detection was performed in electron impact mode with a detector temperature of $230^{\circ} \mathrm{C}$. These experimental systems were used for the reactions of 3-methylfuran with $\mathrm{OH}$ and $\mathrm{NO}_{3}$ radicals and $\mathrm{Cl}$ atoms; (b) in a $50 \mathrm{~L}$ Pyrex glass cell equipped with eight actinic fluorescent lamps $\left(\lambda_{\max }=360 \mathrm{~nm}\right)$ with in situ FTIR analysis for $\mathrm{OH}$ and $\mathrm{NO}_{3}$ radicals; and (c) in a $1080 \mathrm{~L}$ quartz-glass reactor equipped with 10 low-pressure mercury lamps $\left(\lambda_{\max }=254 \mathrm{~nm}\right)$ and 10 superactinic fluorescent lamps $\left(\lambda_{\max }=360 \mathrm{~nm}\right)$ coupled with in situ FTIR analysis for $\mathrm{Cl}$ atoms. Details of this experimental set-up can be found elsewhere (Barnes et al., 1994).

In the quantitative analysis carried out by GC/FID, the response factor (RF) of each compound was determined by introducing different measured amounts of authentic standards (which covered the range of experimental conditions) into the Teflon chamber and conducting several replicate analyses with the coated SPME fibre. The response factor of each compound was calculated with the expression:

Area $=\mathrm{RF} \times[$ product $]$

where the area is quantified from the GC/FID chromatogram and the concentration of the product is known. For compounds that were not commercially available or the yield of the pure compound was not sufficient to carry out the calibration, only an estimation of yield was possible using the ECN (effective carbon number) method (Scalon and Willis, 1985).

In the FTIR analysis, a spectral subtraction procedure was used to derive the concentrations of 3-methylfuran and products as a function of the reaction time. Identification and quantification of 3-methylfuran and products in the $\mathrm{Cl}$ reactions was carried out using calibrated reference spectra. The calibrated spectra were either produced by introducing a known concentration of an authentic sample of the 
Table 1. Rate coefficients for the reactions of 3-methylfuran with $\mathrm{OH}$ and $\mathrm{NO}_{3}$ radicals at atmospheric pressure and room temperature.

\begin{tabular}{|c|c|c|c|c|c|c|}
\hline Reaction & Reference & $k_{\mathrm{S}} / k_{\mathrm{R}}^{\mathrm{a}}$ & $\begin{array}{l}k_{298 \mathrm{~K}^{\prime}}^{\mathrm{b}} \\
10^{-10} \mathrm{~cm}^{3} \\
\text { molec }^{-1} \mathrm{~s}^{-1}\end{array}$ & $\begin{array}{l}\bar{k}_{298 \mathrm{~K}} / \\
10^{-10} \mathrm{~cm}^{3} \\
\text { molec }^{-1} \mathrm{~s}^{-1}\end{array}$ & Method & $\begin{array}{l}\text { Bibliographic } \\
\text { reference }\end{array}$ \\
\hline \multirow[t]{5}{*}{ 3-Methylfuran + OH } & trans-2-Butene & $1.11 \pm 0.09$ & $0.81 \pm 0.16$ & \multirow{4}{*}{$1.1 \pm 0.2^{c}$} & loop/GC-MS & This work \\
\hline & 5-Methylfurfural & $2.27 \pm 0.08$ & $1.16 \pm 0.06$ & & SPME/GC-FID & This work \\
\hline & trans-2-Butene & $1.24 \pm 0.08$ & $0.91 \pm 0.17$ & & FTIR & This work \\
\hline & Propene & $3.6 \pm 0.3$ & $1.08 \pm 0.17$ & & FTIR & This work \\
\hline & 2,3-Dimethyl-2-butene & - & - & $0.9 \pm 0.2$ & FTIR & Atkinson et al. (1989) \\
\hline \multirow[t]{5}{*}{ 3-Methylfuran $+\mathrm{NO}_{3}$} & 2-Methyl-2-butene & $1.36 \pm 0.02$ & $0.13 \pm 0.01$ & \multirow{3}{*}{$0.13 \pm 0.02^{\mathrm{c}}$} & Loop/GC-FID & This work \\
\hline & 2-Methyl-2-butene & $1.01 \pm 0.05$ & $0.09 \pm 0.02$ & & FTIR & This work \\
\hline & $\alpha$-Pinene & $2.0 \pm 0.1$ & $0.116 \pm 0.009$ & & FTIR & This work \\
\hline & 2-Methyl-2-butene & - & - & $0.13 \pm 0.05$ & GC/FID & Alvarado et al. (1996) \\
\hline & 2,3-Dimethyl-2-butene & - & - & $0.286 \pm 0.006$ & GC/FID & Kind et al. (1996) \\
\hline
\end{tabular}

a Indicated errors are two least-squares standard deviations.

b Placed on an absolute basis by use of rate constants $k_{\mathrm{R}}$ for the reactions of $\mathrm{OH}$ radicals with trans-2-butene, 5-methylfurfural and propene at 298 $\mathrm{K}$ of $(7.31 \pm 1.31) \times 10^{-11} \mathrm{~cm}^{3}$ molec ${ }^{-1} \mathrm{~s}^{-1}$ (Edney et al., 1986), $(5.10 \pm 0.20) \times 10^{-11} \mathrm{~cm}^{3}$ molec ${ }^{-1} \mathrm{~s}^{-1}$ (Bierbach et al., 1995) and (3.01 \pm 0.42$) \times 10^{-12} \mathrm{~cm}^{3} \mathrm{molec}-1 \mathrm{~s}^{-1}\left(\mathrm{Nielsen}^{-1}\right.$ al., 1990), respectively; and a rate constant $k_{\mathrm{R}}$ for the reactions of $\mathrm{NO}_{3}$ radicals with 2-methyl-2-butene and $\alpha$-Pinene of $(9.38 \pm 3.32) \times 10^{-12} \mathrm{~cm}^{3}$ molec ${ }^{-1} \mathrm{~s}^{-1}$ (Atkinson, 1991 ) and (5.90 \pm 0.4$) \times 10^{-12} \mathrm{~cm}^{3}$ molec $^{-1} \mathrm{~s}^{-1}$ (Martínez et al., 1998).

$\mathrm{c}$ Weighted mean.

compound into the reactor or were taken from an existing IR spectral library bank.

Yields were calculated by plotting the amounts of product formed at each time $t$ against the amounts of 3-methylfuran consumed at each time $t$.

\subsubsection{Cl products}

The experiments involving SPME GC/MS and GC/FID/ECD techniques were conducted in a Teflon bag $(\approx 150 \mathrm{~L})$ placed inside a chamber with four $254 \mathrm{~nm}$ blacklamps. Photolysis of thionyl chloride $\left(\mathrm{SOCl}_{2}\right)$ or trichloroacetyl chloride $\left(\mathrm{CCl}_{3} \mathrm{COCl}\right)$ was used to generate atomic chlorine in irradiation steps of 8 to $10 \mathrm{~s}$ for $\mathrm{SOCl}_{2}$ and 10 to $60 \mathrm{~s}$ for $\mathrm{CCl}_{3} \mathrm{COCl}$. The total photolysis time was 30-90 s for $\mathrm{SOCl}_{2}$ and $22-$ $720 \mathrm{~s}$ for $\mathrm{CCl}_{3} \mathrm{COCl}$, with conversion of 3-methylfuran in the range $21-94 \% . \mathrm{Cl}_{2}$ was not used as the source of $\mathrm{Cl}$ atoms because $\mathrm{Cl}_{2}$ reacts with 3-methylfuran at the concentration used for this study. All experiments were carried out in the absence of $\mathrm{NO}$ and only one qualitative experiment was carried out in the presence of NO. The initial concentrations of the reactants (in molecule $\mathrm{cm}^{-3}$ units) were as follows: [3-methylfuran] $=(4.9-29) \times 10^{13},\left[\mathrm{CCl}_{3} \mathrm{COCl}\right]=$ $(1.4-2.4) \times 10^{14},\left[\mathrm{SOCl}_{2}\right]=(4.4-19) \times 10^{13}$ and $[\mathrm{NO}]=$ $3.4 \times 10^{13}$. Electron impact (EI) and chemical ionization (CI with methane as the ionization gas) modes were used in mass spectrometry detection in order to identify and obtain molecular weight information on the different reaction products. In addition, an electron capture detector (ECD) was used to identify some reaction products. The quantitative analysis was performed in the GC/FID using $\mathrm{SOCl}_{2}$ as the $\mathrm{Cl}$ source. The total photolysis time was in the range of $60-100 \mathrm{~s}$ in order to achieve 60-90\% conversion of 3-methylfuran.
In FTIR experiments using the cylindrical $1080 \mathrm{~L}$ quartzglass reactor, $\mathrm{Cl}$ atoms were generated by the photolysis of $\mathrm{ClCOCOCl}$ and $\mathrm{Cl}_{2}$ using 10 low-pressure mercury lamps and 8 superactinic fluorescence lamps, respectively. The total photolysis time was 11-25 min for $\mathrm{ClCOCOCl}$ and $23 \mathrm{~min}$ for $\mathrm{Cl}_{2}$ and, under these conditions, the 3-methylfuran conversion was 33-95\%. The reaction between 3-methylfuran and $\mathrm{Cl}_{2}$ was found to be negligible in the quartz-glass reactor under the conditions used. The use of molecular chlorine as the source of $\mathrm{Cl}$ atoms, therefore, avoided potential photolysis at $254 \mathrm{~nm}$ of the products generated in the reaction.

The initial concentrations of the reactants (in molecule $\mathrm{cm}^{-3}$ units) were as follows: [3-methylfuran] = $(1.9-2.9) \times 10^{13},\left[\mathrm{Cl}_{2}\right]=(4.9-7.3) \times 10^{13}$ and $[\mathrm{ClCOCOCl}]$ $=1.2 \times 10^{13}$. The reactant and the products were monitored in situ using a multi-reflection White mirror system $(5.6 \mathrm{~m}$ base length, $498 \mathrm{~m}$ total path length) mounted in the reactor and coupled to an FTIR spectrophotometer (Thermo Nicolet Nexus) equipped with a $\mathrm{KBr}$ beam splitter and MCT detector. The IR spectra were recorded in the $700-4000 \mathrm{~cm}^{-1}$ spectral range with a resolution of $1 \mathrm{~cm}^{-1}$ by co-adding 64 interferograms over $60 \mathrm{~s}$. In typical experiments 25 spectra were recorded over a period of $25 \mathrm{~min}$ with light.

\subsubsection{OH products}

The qualitative determination of products was carried out using GC/MS and FTIR analysis and quantitative determination was performed using GC/FID. Two $\mathrm{OH}$ precursors were used in the GC/MS product studies in order to assess the influence of $\mathrm{NO}$ on the reaction mechanisms: $\mathrm{H}_{2} \mathrm{O}_{2}$ photolysed from $60 \mathrm{~s}$ to $60 \mathrm{~min}$ with the $254 \mathrm{~nm}$ lamps and $\mathrm{CH}_{3} \mathrm{ONO}$ in the presence of NO photolysed from 20 to $30 \mathrm{~s}$ with the 
$360 \mathrm{~nm}$ lamps. After each photolysis a chromatogram was recorded and the total photolysis times of 150-180 s and 106 min for $\mathrm{CH}_{3} \mathrm{ONO}$ and $\mathrm{H}_{2} \mathrm{O}_{2}$ were attained, respectively, to give 75-99\% depletion of 3-methylfuran in the first case and 36\% depletion in the second case. The initial reactant concentrations in the chamber (in molecule $\mathrm{cm}^{-3}$ ) were as follows: $\left[\mathrm{CH}_{3} \mathrm{ONO}\right]=(1.3-2.1) \times 10^{14},[\mathrm{NO}]=(3.2-$ $4.4) \times 10^{13},[3$-methylfuran $]=(3.6-12) \times 10^{13}$ and $\left[\mathrm{H}_{2} \mathrm{O}_{2}\right]$ $=2.8 \times 10^{14}$. In the quantitative analysis only $\mathrm{CH}_{3} \mathrm{ONO}$ was used as the $\mathrm{OH}$ source.

In FTIR product experiments $\mathrm{CH}_{3} \mathrm{ONO}$ was photolysed continuously with eight $360 \mathrm{~nm}$ lamps and this led to the conversion of up to $70 \%$ of the 3-methylfuran. The FTIR system used was the same as that described for the kinetic studies. The initial concentrations in the cell (in molecule $\mathrm{cm}^{-3}$ ) were as follows: $\left[\mathrm{CH}_{3} \mathrm{ONO}\right]=2.6 \times 10^{14}$, $[\mathrm{NO}]=2.6 \times 10^{14}$ and [3-methylfuran] $=2.6 \times 10^{14}$.

\subsection{3 $\mathrm{NO}_{3}$ products}

The products were identified by GC/FID/MS and FTIR spectroscopy. In the GC/FID/MS experiments the initial concentration of 3-methylfuran in the chamber (in molecule $\mathrm{cm}^{-3}$ ) was $4.7 \times 10^{13}$. Successive additions of $\mathrm{N}_{2} \mathrm{O}_{5}$ were performed corresponding to a final concentration of $2.4 \times 10^{13}$ molecule $\mathrm{cm}^{-3}$, which resulted in the depletion of approximately $95 \%$ of the 3-methylfuran. In the FTIR experiments, the initial concentrations in the reactor (in molecule $\mathrm{cm}^{-3}$ ) were as follows: $\left[\mathrm{N}_{2} \mathrm{O}_{5}\right]=(2.8-2.9) \times 10^{14}$ and [3-methylfuran] $=(2.4-2.9) \times 10^{14}$ to achieve $17 \%$ conversion of 3-methylfuran.

\subsubsection{Chemicals}

The chemicals and their stated purities were as follows: 3-methylfuran (Acros, 98\%), 5-methylfurfural (Aldrich, 99\%), 3-furaldehyde (Aldrich, +97\%), $\alpha$-pinene (Fluka, 99\%), 3-methyl-2,5-furanodione (Acros, 98\%), 3-methyl-2(5H)-furanone (Aldrich, 90\%), 5-hydroxy-4methyl-2(5H)-furanone (Ochem, 97\%), crotonaldehyde (Aldrich, 99\%), acetic acid (Aldrich, +99.99\%), 2methylpropenoic acid (Aldrich, 99\%), 2-butenoic acid (Aldrich, 98\%), $\mathrm{SOCl}_{2}$ (Aldrich, +99\%), $\mathrm{CCl}_{3} \mathrm{COCl}$ (Aldrich, 99\%) and $\mathrm{ClCOCOCl}$ (Aldrich, 98\%). Gaseous products: trans-2-butene (Aldrich, $+99 \%$ ), propene (Aldrich, +99\%), 2-methyl-2-butene (Aldrich, +99\%), $\mathrm{Cl}_{2}$ (Praxair, $>99.8 \%$ ), $\mathrm{N}_{2}$ (Praxair, 99.999\%), air (Praxair, 99.999\%) and NO (Praxair, 99\%). The following compounds were used in methylnitrite synthesis: $\mathrm{NaNO}_{2}$ (Panreac, 97\%), $\mathrm{H}_{2} \mathrm{SO}_{4}$ (Panreac, 95-98\%) and $\mathrm{CaCO}_{3}$ (Riedel-de-Haën AG, 99\%). In $\mathrm{N}_{2} \mathrm{O}_{5}$ synthesis: $\mathrm{N}_{2} \mathrm{O}_{4}$ (Fluka, $>98.5 \%$ ) and $\mathrm{O}_{2}$ (Praxair, 99.999\%). Hydroxymethyl-2(5H)-furanones [5hydroxy-3-methyl-( $5 H)$-furanone and 5-hydroxy-4-methyl$2(5 \mathrm{H})$-furanone] were prepared from 3-methylfuran according to Kumar and Pandey (2000). The product was characterised by GC-MS.

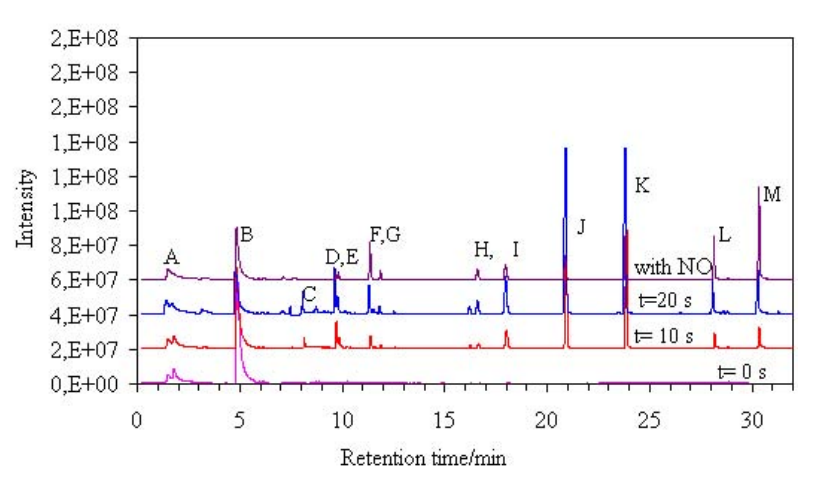

Fig. 1. Experimental chromatograms for the reactions of 3methylfuran with chlorine atoms from SPME-GC/MS experiments.

\section{Results and discussion}

\subsection{Kinetic studies}

The data obtained for reactions of 3-methylfuran with $\mathrm{OH}$ and $\mathrm{NO}_{3}$ radicals are plotted in accordance with Eqs. (1) and (2) (see Fig. 1 in the Supplement). The data give straight lines that pass through the origin with a slope of $k_{S} / k_{R}$, indicating that secondary reactions or heterogeneous processes are insignificant. The error limit for the ratio of rate coefficients $k_{\mathrm{S}} / k_{\mathrm{R}}$ obtained from least-squares analyses includes only the precision of the fit to our experimental data $( \pm 2 \sigma)$. These rate constant ratios $k_{\mathrm{S}} / k_{\mathrm{R}}$ are placed on an absolute basis using the recommended rate constants $k_{\mathrm{R}}$ for the reference compounds. The $k_{\mathrm{S}}$ error limit, $\sigma_{k \mathrm{~S}}$, was calculated taking into account the error limit from the slopes obtained from the regression analysis and the quoted error in the value of the rate coefficient for the reference compound. The weighted mean $k_{\mathrm{S}}$ values and the rate coefficient ratios $k_{\mathrm{S}} / k_{\mathrm{R}}$ obtained by GC/FID and FTIR techniques are given in Table 1 together with the data available in literature.

The data show that within error there is no significant difference between runs monitored by GC/FID/MS or FTIR. As can be seen from the results in Table 1, the high values of the $\mathrm{OH}$ rate coefficients (in the order of $10^{-10} \mathrm{~cm}^{3}$ molecule ${ }^{-1} \mathrm{~s}^{-1}$ ) show the high reactivity of $\mathrm{OH}$ radicals towards 3 -methylfuran. The weighted mean rate coefficient data obtained for the reaction of 3-methylfuran with $\mathrm{OH}$ are slightly higher than the literature data (Atkinson et al., 1989) but these can be considered similar due to experimental errors. The rate coefficients for $\mathrm{OH}$ reactions can be estimated by the AOPWIM programme from the SAR method (Aschmann and Atkinson, 1995). The rate constant calculated in this way for 3-methylfuran and $\mathrm{OH}$ is $1.05 \times 10^{-10} \mathrm{~cm}^{3}$ molecule ${ }^{-1} \mathrm{~s}^{-1}$, which is similar to the average rate coefficient value obtained in this work.

In relation to the reaction of 3-methylfuran with $\mathrm{NO}_{3}$, the rate constant obtained in this work is consistent with the data obtained by Alvarado et al. (1996). A mean value between the rate constants for $\mathrm{OH}$ and $\mathrm{NO}_{3}$ radicals determined in 
this study and the ones obtained by Atkinson et al. (1989) and Alvarado et al. (1996) can, therefore, be proposed as a good reference value.

On the basis of the rate coefficients reported in Table 1 for the reaction of 3-methylfuran with $\mathrm{OH}$ and $\mathrm{NO}_{3}$ radicals, together with data for $\mathrm{Cl}$ atoms reported in our previous work (Cabañas et al., 2005), the following order of reactivity can be established: $k_{\mathrm{Cl}}>k_{\mathrm{OH}}>k_{\mathrm{NO}_{3}}$. A comparative study of these rate coefficients with values available in the literature for mono- and dimethylated furans was reported in a previous publication by Cabañas et al. (2005).

\subsection{Product studies}

The major challenge in identifying the reaction products from the reaction of 3-methylfuran with $\mathrm{OH}, \mathrm{NO}_{3}$ radicals and $\mathrm{Cl}$ atoms is the scarcity of commercially available standards. The identification of reaction products was carried out using the custom GC-MS and FTIR libraries created after the injection of commercial products, compounds synthesized in our laboratory, data from commercial GC-MS libraries (NIST 21, NIST 27, NIST 107, NIST 147 and WILEY 229) and Aldrich Library FTIR spectra (Pounchert, 1989).

\subsubsection{Reaction with $\mathrm{Cl}$ atoms}

An example of a typical GC-MS chromatogram is shown in Fig. 1 for the oxidation of 3-methylfuran by $\mathrm{Cl}$ atoms in the absence of $\mathrm{NO}$ at different reaction times and in the presence of NO (upper chromatogram). Peaks A and C represent artefact compounds from the chlorine source and from the fibre, respectively, and 3-methylfuran is represented by peak B. The compounds identified by the mass spectra and by the retention times of authentic standards are 3furaldehyde (peak D), 3-methyl-2,5-furanodione (peak $\mathrm{H}$ ) and 3-methyl-2(3H)-furanone (peak I). Analysis of the EI mass spectrum of peak $\mathrm{E}$ shows the presence of the compound $\mathrm{C}_{5} \mathrm{H}_{6} \mathrm{O}_{2}$ and the chemical ionization (CI) mass spectrum of this peak shows that its molecular weight is 98 . This peak can, therefore, be tentatively assigned to an isomer of 3methyl-2(3H)-furanone or 2-methylbutenedial. Peaks F and $\mathrm{G}$ are assigned to $(E / Z)$-2-methylbutenedial based on the EI fragmentation and by comparison of the mass spectrum with the reference mass spectrum and the retention time of the synthesized compound (see Fig. 2a and b). Peaks L and $\mathrm{M}$ are provisionally assigned to 5-hydroxy-3-methyl-2(5H)furanone and 5-hydroxy-4-methyl-2(5H)-furanone, respectively, based on EI fragmentations and the CI mass spectra, which indicate that the molecular weight is 114 . The synthesis of the isomers of hydroxy-methylfuranones and the comparison with the commercial 5-hydroxy-4-methyl$2(5 \mathrm{H})$-furanone confirmed the identification of these compounds (see Fig. 2c and d). Peaks J and K, with retention times of 20.9 and 23.9 min, respectively, are the most intense and were identified as chlorinated organic com-
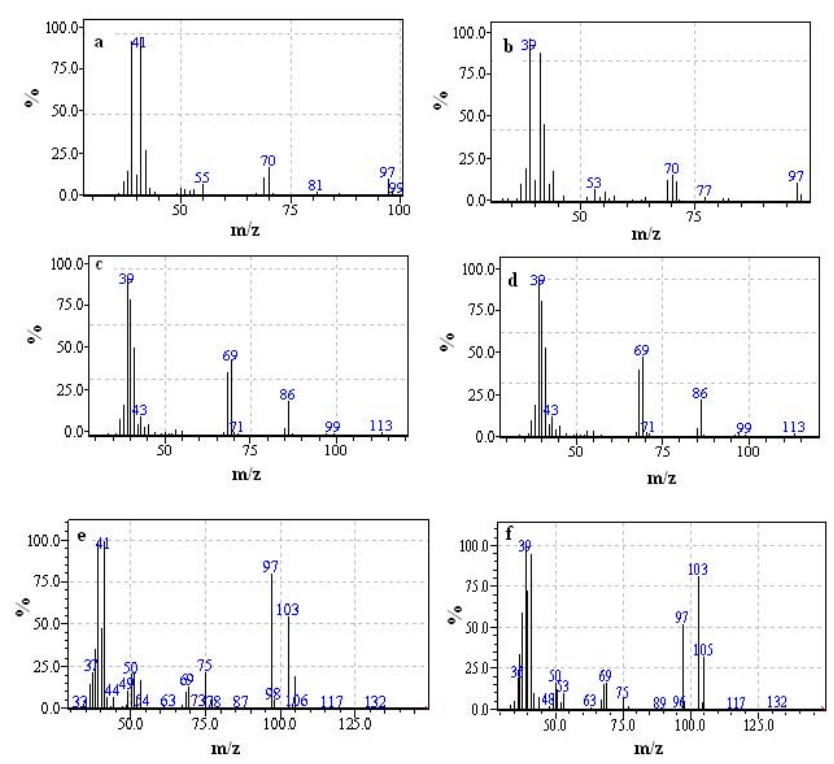

Fig. 2. (a) Experimental electron impact mass spectra (EI-MS) of peaks $\mathrm{F}(\mathrm{tr}=11.4 \mathrm{~min})$ and $\mathrm{G}(\mathrm{tr}=11.8 \mathrm{~min})$. (b) Experimental electron impact mass spectrum (EI-MS) of the 2-methylbutenedial synthesized. (c) Experimental electron impact mass spectrum (EIMS) of peak $L(\operatorname{tr}=28.2 \mathrm{~min})$. (d) Experimental electron impact mass spectrum (EI-MS) of the commercial 5-hydroxy-4-methyl2(5H)-furanone. (e, f) Mass spectra by electron impact ionization (EI) of peaks $\mathrm{J}$ and $\mathrm{K}$ assigned to a molecular formula $\mathrm{C}_{5} \mathrm{H}_{5} \mathrm{O}_{2} \mathrm{Cl}$.

pounds of molecular formula $\mathrm{C}_{5} \mathrm{H}_{5} \mathrm{O}_{2} \mathrm{Cl}$ based on the following evidence: (a) the $\mathrm{CI}$ mass spectrum shows that the molecular ion is at $m / z, 132$, (b) the fragmentation pattern from the electron impact mass spectrum is also consistent with this compound and (c) the gas chromatogram obtained with electron capture detection (ECD), which is particularly sensitive to chlorinated compounds, shows only two intense peaks at 20.9 and $23.9 \mathrm{~min}$ (see Fig. 2 in the Supplement). The EI spectra of peaks $J$ and $\mathrm{K}$ are shown in Fig. 2e and f. Additionally, in previous experiments 5chloro-2 $(5 H)$-furanone was detected as a product from the reactions of furan (Villanueva et al., 2007), 2-methylfuran and 2-ethylfuran (Villanueva et al., 2009) with $\mathrm{Cl}$ atoms. It is, therefore, believed that peaks $\mathrm{J}$ and $\mathrm{K}$ can be assigned to chlorinated methylfuranones [5-chloro-3-methyl-2(5H)furanone and 5-chloro-4-methyl-2(5H)-furanone]. Peaks J and $\mathrm{K}$ could also be assigned to acid chlorides (3-methyl-4oxo-2-butenoyl chloride or 2-methyl-4-oxo-2-butenoyl chloride) $\left[\mathrm{HOC}-\mathrm{CH}=\mathrm{C}\left(\mathrm{CH}_{3}\right)-\mathrm{COOH}\right]$ in the same way as 4oxo-2-pentenoyl chloride was identified in the reaction of 2-methylfuran with $\mathrm{Cl}$ atoms. As described below for the FTIR analysis, the chlorinated methylfuranones are probably the compounds that are formed to the greatest extent. As shown in Fig. 1, the reaction products in the absence and in the presence of NO are similar. The only difference probably concerns the yields. 


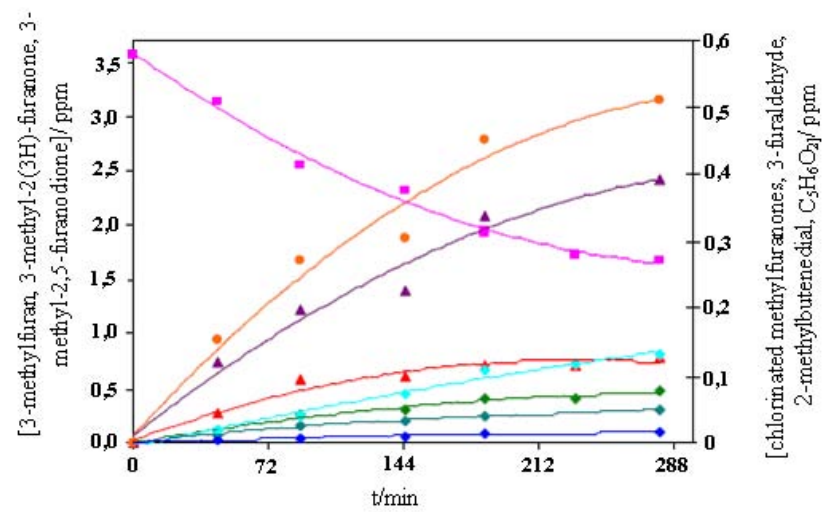

Fig. 3. Concentration-time profiles of 3-methylfuran and products identified in the reaction of 3-methylfuran with $\mathrm{Cl}$ atoms anal-

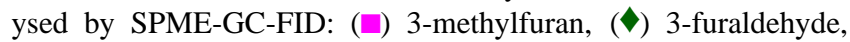
$(\diamond)$ furanone isomer, $\mathrm{C}_{5} \mathrm{H}_{6} \mathrm{O}_{2},(\Delta)$ 2-methylbutenedial, ( $\left.\diamond\right)$ 3methyl-2(3H)-furanone, ( $)$ 3-methyl-2,5-furanodione, ( $\mathbf{\Delta}$ ) chlorinated methylfuranone, $(\bullet)$ chlorinated methylfuranone.

The yields of some compounds were estimated using the response factors of structurally related and commercially available compounds (i.e., the ECN method). The response factor for 2-methylbutenedial, its isomer (peak E) and chlorinated methylfuranones were estimated by taking into account the response factor of 3-methyl-2(5H)-furanone.

An example of the concentration/time profiles for the identified products in the $\mathrm{Cl}$ atom initiated oxidation of 3-methylfuran is shown in Fig. 3. The curve contours for chlorinated methylfuranones, 3-furaldehyde and 2methylbutenedial indicate that these are primary products. In the case of 3-furaldehyde, this fact is more evident in the plots obtained from FTIR analysis.

FTIR spectra recorded at different stages of the reaction of 3-methylfuran with $\mathrm{Cl}$ are shown in Fig. 4a: (a) spectrum of 3-methylfuran $+\mathrm{Cl}_{2}$ in air before photolysis, (b) spectrum of 3-methylfuran and products after 15 min of photolysis (absorptions from $\mathrm{CO}_{2}$ have been zeroed due to saturation of the band and those from $\mathrm{H}_{2} \mathrm{O}$ have been subtracted), and (c) residual product spectrum after subtraction of 3-methylfuran. The residual spectrum of the products shows the presence of $\mathrm{HCl}$ and $\mathrm{CO}$, a band with a high intensity at $1825 \mathrm{~cm}^{-1}$, bands of medium intensity in the region $800-1300 \mathrm{~cm}^{-1}$ and two bands of low intensity in the carbonyl region at 1710 and $1665 \mathrm{~cm}^{-1}$. Based on the results obtained by SPME-GC/MS the band at $\sim 1710 \mathrm{~cm}^{-1}$ is assigned to 3-furaldehyde - an assignment also based on a comparison with the reference spectrum. The bands at $\sim 1703$ and $1665 \mathrm{~cm}^{-1}$ can be tentatively assigned to 2-methylbutenedial, but due to the low purity of the 2-methylbutenedial synthesized this can not be confirmed from the IR spectrum alone.

Based on the GC/MS results and those obtained in our previous studies on the reaction of $\mathrm{Cl}$ atoms with furan (Villanueva et al., 2007), 2-methylfuran and 2-ethylfuran
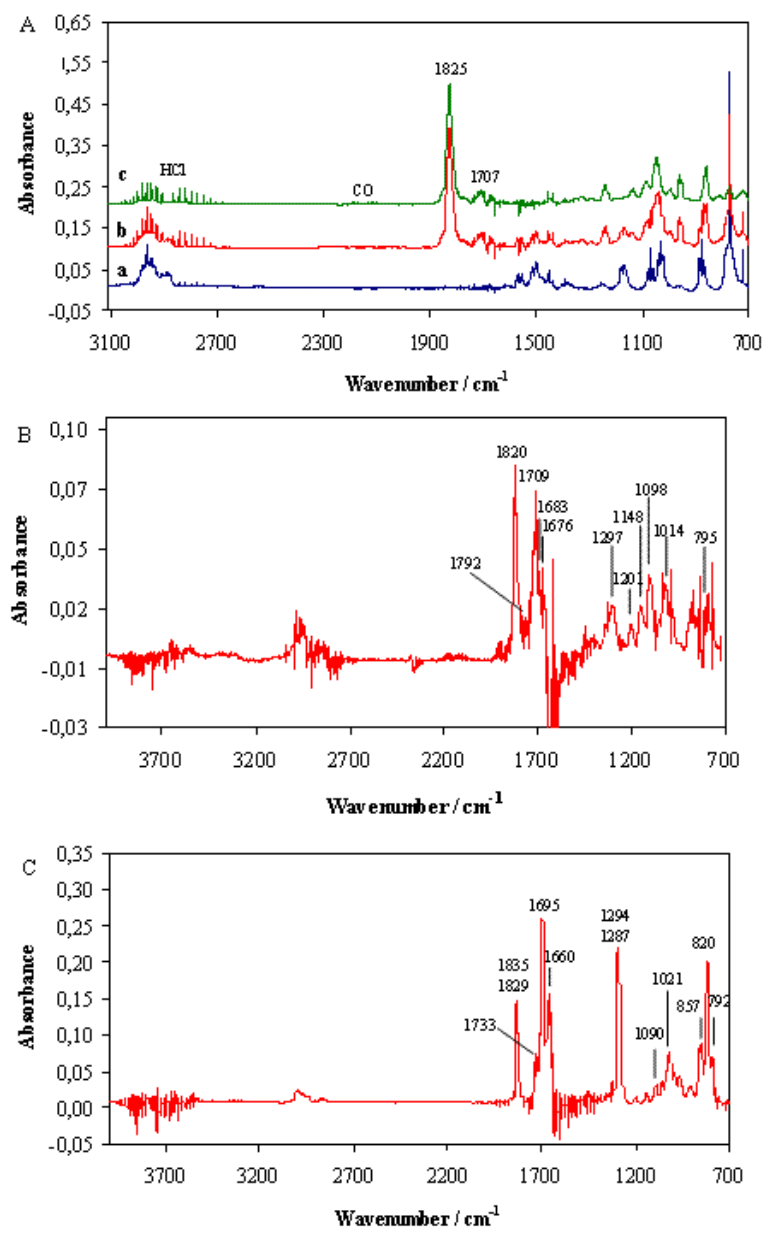

Fig. 4. Experimental infrared absorption spectra from the reaction of: (A) 3-methylfuran with chlorine atoms (a) before photolysis, (b) after 15 min of photolysis (c) residual spectrum from b after subtraction of 3-methylfuran, $\mathrm{H}_{2} \mathrm{O}$ with the $\mathrm{CO}_{2}$ absorption zeroed; (B) 3-methylfuran with hydroxyl radical (residual spectrum of products after 8 min of reaction), (C) 3-methylfuran with nitrate radicals (residual spectrum of products after $3.4 \mathrm{~min}$ of reaction).

(Villanueva et al., 2009), the band at $1825 \mathrm{~cm}^{-1}$ can be assigned to the chlorinated methylfuranone isomers 5-chloro-3-methyl-2 $(5 H)$-furanone and 5-chloro-4-methyl$2(5 H)$-furanone, because this band is very similar in appearance to that observed for 5-chloro-2 $(5 H)$-furanone. The possibility that this band could correspond to an acid chloride (3-methyl-4-oxo-2-butenoyl chloride or 2-methyl-4-oxo-2butenoyl chloride) was ruled out as the infrared spectrum is devoid of any absorption bands in the region 2695$2900 \mathrm{~cm}^{-1}$, which would be characteristic of the stretching vibration of $\mathrm{C}-\mathrm{H}$ in the $-\mathrm{CHO}$ group.

The gas-phase IR absorption coefficients for chlorinated methylfuranones are not known. As a consequence, the concentrations of these compounds were estimated by applying the Beer-Lambert Law for the absorption band at $1825 \mathrm{~cm}^{-1}$ using the known absorption coefficient for the structurally 
Table 2. Yields of products $(\% \mathrm{C})$ detected in the reaction of 3-methylfuran with chlorine atoms at room temperature and atmospheric pressure. The errors quoted in the table are a combination of the $2 \sigma$ statistical errors from the regression analysis and the errors from the spectral subtraction procedure in the case of FTIR or of the calibration curve in the case of SPME-GC/FID.

\begin{tabular}{|c|c|c|c|c|c|}
\hline \multicolumn{4}{|c|}{ Reaction products } & \multicolumn{2}{|l|}{ Molar Yield (\%) } \\
\hline Rt (min) & MW & name & Structure & SPME/GC-FID & FTIR \\
\hline 9.7 & 96 & 3-furaldehyde & & $7 \pm 2^{\mathrm{a}}$ & $9 \pm 1^{\mathrm{b}}$ \\
\hline 9.8 & 98 & Isomer of 3-methyl-2(5H)-furanone & $\mathrm{C}_{5} \mathrm{H}$ & $2 \pm 1^{\mathrm{a}}$ & - \\
\hline 16.7 & 112 & 3-methyl-2,5-furanodione & & $8 \pm 1^{\mathrm{a}}$ & \\
\hline $11.4 / 11.8$ & 98 & 2-methylbutenedial & $\mathrm{HOC}-\mathrm{CH}=\mathrm{C}\left(\mathrm{CH}_{3}\right)-\mathrm{CHO}$ & $4 \pm 1^{\mathrm{a}}$ & detected \\
\hline 18 & 98 & 3-methyl-2(3H)-furanone & & $10 \pm 2^{\mathrm{a}}$ & - \\
\hline $\begin{array}{l}20.9 \\
23.9\end{array}$ & $\begin{array}{l}132 \\
132\end{array}$ & $\begin{array}{l}\text { 5-chloro-3-methyl-2 }(5 H) \text {-furanone } \\
\text { 5-chloro-4-methyl-2 }(5 H) \text {-furanone }\end{array}$ & & $\begin{array}{l}>16^{\mathrm{a}} \\
>25^{\mathrm{a}}\end{array}$ & $81 \pm 9^{\mathrm{c}}$ \\
\hline 28.2 & 114 & 5-hydroxy-3-methyl-2(5H)-furanone & & detected & - \\
\hline \multirow[t]{3}{*}{30.2} & 114 & 5-hydroxy-4-methyl-2(5H)-furanone & & detected & - \\
\hline & & Hydrochloric acid & $\mathrm{HCl}$ & - & $34 \pm 4^{\mathrm{b}}$ \\
\hline & & Carbon monoxide & $\mathrm{CO}$ & - & detected \\
\hline
\end{tabular}

${ }^{\mathrm{a}}$ Average of 5 experiments with UV lamps; ${ }^{\mathrm{b}}$ only 1 experiment with VIS lamps; ${ }^{\mathrm{c}}$ average of 8 experiments with UV and VIS lamps.

related compound $2(5 \mathrm{H})$-furanone. The calculated yield of chlorinated methylfuranones is the sum of the concentrations of the two isomers as the IR spectrum is a mixture of the two individual ones. The yield of $\mathrm{CO}$ was not calculated because it is a secondary product that only appears at the end of the reaction.

The product yields were calculated from the slopes of plots of products formed versus 3-methylfuran reacted. The concentrations of the reaction products were calculated using the mathematical formalism of Tuazon et al. (1986), where the loss processes such as photolysis and wall loss have been taken into account. For 3-furaldehyde the reaction with the $\mathrm{Cl}$ atoms was also considered using the rate coefficient obtained by Cabañas et al. (2008). A quantitative analysis in the presence of $\mathrm{NO}$ was not performed due to the occurrence of secondary reactions that involve the formation of $\mathrm{OH}$ in the reaction system (Wang et al., 2005). The molar yields obtained for the products identified by SPME/GC-FID and FTIR are given in Table 2 together with their retention times and molecular weights. The total error is a combination of statistical error $2 \sigma$ obtained in a regression analysis and uncertainties estimated in the calibrations. Although it was not possible to quantify all of the identified compounds, if we compare the results from the quantification methods (SPME-
GC/FID and FTIR) it is clear that chlorinated methylfuranones are the major gas-phase reaction products in the reaction between $\mathrm{Cl}$ atoms and 3-methylfuran. Despite the overall uncertainties associated with each quantification method, the yields of the products are in fair quantitative agreement. A total carbon mass balance of $70 \%$ was obtained for the products detected in GC-FID experiments and $90 \%$ for the products determined by FTIR. These values must be treated with caution because the yield of chlorinated methylfuranones could be underestimated by GC-FID, as occurred in the case of the chlorinated furanone formed from furan and alkylfurans with $\mathrm{Cl}$ atoms, or overestimated in the case of FTIR (Villanueva et al., 2007, 2009).

\subsubsection{Reaction with $\mathrm{OH}$ radicals}

A typical GC-MS chromatogram of the reaction sample from the oxidation of 3-methylfuran by $\mathrm{OH}$ radicals in the presence of $\mathrm{NO}$ using $\mathrm{CH}_{3} \mathrm{ONO}$ as a precursor for $\mathrm{OH}$ shows the same peaks as obtained in reaction of 3-methylfuran with $\mathrm{Cl}$ atoms - except for two peaks (see Fig. 3 in the Supplement). The compounds identified by the mass spectrum and by the retention time of authentic standards are acetic acid, 3furaldehyde, 2-methylbutenedial, 3-methyl-2,5-furanodione, 
3-methyl-2(3H)-furanone and 5-hydroxy-4-methyl-2(5H)furanone. 5-Hydroxy-4-methyl-2(5H)-furanone was assigned by comparison with the mass spectrum and retention time of the commercial compound (see mass spectra $\mathrm{c}$ and $\mathrm{d}$ in Fig. 2). The presence of a compound of formula $\mathrm{C}_{5} \mathrm{H}_{6} \mathrm{O}_{2}$ was evident, but this was not assigned to any particular structure. The qualitative SPME-GC/MS analysis carried out using $\mathrm{H}_{2} \mathrm{O}_{2}$ as a clean source of $\mathrm{OH}$ shows the same peaks as obtained using methylnitrite, along with five new peaks that are very weak. Three of the new peaks were identified as being due to crotonaldehyde, 2-methylpropenoic acid and 2butenoic acid by their mass spectra and retention times of authentic samples. Two peaks at 22.4 and $22.8 \mathrm{~min}$ were identified from the library as 4-methyl-2 $(5 H)$-furanone and methylsuccinic anhydride, but this is only a tentative identification because they were not compared with commercial standards. All of these new peaks can only be explained as being due to secondary reactions products, probably through photolysis $(\lambda=254 \mathrm{~nm})$ of primary reaction products.

The yields in $\% \mathrm{C}$ for 2-methylbutenedial, 3-furaldehyde, 3-methyl-2,5-furandione and 3-methyl-2(3H)-furanone were $1.4 \pm 0.3,3.9 \pm 1.8,18.1 \pm 4.6$ and $1.6 \pm 0.2$, respectively.

In order to complete or confirm the results obtained with SPME/GC-MS, different experiments using FTIR analysis were performed. However, the reaction products were only tentatively assigned due to the low signal intensity. The residual FTIR spectrum for the product obtained in the oxidation of 3-methylfuran with $\mathrm{OH}$ radicals in the presence of NO is shown in Fig. $4 \mathrm{~b}$ after subtraction of the spectra of 3-methylfuran, $\mathrm{NO}_{2}, \mathrm{NO}, \mathrm{HCHO}, \mathrm{HNO}_{3}, \mathrm{HONO}$ and $\mathrm{CH}_{3} \mathrm{ONO}$. Only 3-methyl-2,5-furanodione was identified by comparison with the bands of an authentic standard $\left(898,1792\right.$ and $\left.1858 \mathrm{~cm}^{-1}\right)$. The identification of 2methylbutenedial by FTIR was not possible due to the low purity of the synthesized compound. Nevertheless, the absorption band at $1711 \mathrm{~cm}^{-1}$ (Fig. 4b) was assigned to 2methylbutenedial by comparison with the bands of other 1,4dicarbonyl compounds, such us Z-2-butenedial, and based on the results obtained by GC-MS. 2-Methylbutenedial was identified and quantified [yield of $(83 \pm 33) \%$ ] as a major reaction product by Gómez Álvarez et al. (2009) in the degradation of 3-methylfuran with $\mathrm{OH}$ radicals. The low yield $(1.4 \%)$ obtained in our work could be due to secondary reactions that give products such as 3-methyl-2(3H)-furanone and 3-methyl-2,5-furanodione. In this way, Bierbach et al. (1995) reported that the yield of 4-oxo-2-pentenal (unsaturated 1,4-dicarbonyl compound) in the reaction of 2methylfuran with $\mathrm{OH}$ radicals varied from $\approx 70 \%$ at the beginning of the reaction to $\approx 47 \%$ at the end due to photolysis of the compound and probably to the oxidation of the dicarbonyl compound by OH radicals (Bierbach et al., 1994; Tang and Zhu, 2005). In our experiments a significant decay in the intensity of the band at $1711 \mathrm{~cm}^{-1}$ with time was observed, meaning that a very fast loss process is occurring. The reason why secondary reactions take place to a greater extent in our experiments than in those reported by Bierbach et al. (1995) and Gómez Álvarez et al. (2009) could concern the different experimental conditions used.

Absorption bands at 795, 1297 and $1734 \mathrm{~cm}^{-1}$ observed in the FTIR spectra are typical of nitroperoxy compounds $\left(\mathrm{ROONO}_{2}\right)$ formed from the reaction of peroxy radicals with $\mathrm{NO}_{2}$ (Wängberg et al., 1997; Martín et al., 2002). One of the most intense bands was observed at $1820 \mathrm{~cm}^{-1}$ and this is assigned to a carbonyl group. This band, together with the bands observed at 1014, 1053, 1098 (typical of a C-O stretch of an alcohol group) and the band at $3500-3560 \mathrm{~cm}^{-1}$ (absorption characteristic of $\mathrm{O}-\mathrm{H}$ ), supports the formation of a hydroxy-methylfuranone as the reaction product. Based on the intensities of the peaks obtained by GC/MS, and taking into account that only $24 \%$ of the reacted carbon was identified, it is likely that different hydroxy-methylfuranones had been formed. However, hydroxy-methylfuranones were not quantified due to the low purity of the commercial compound. Compounds such as $\mathrm{CO}\left(2115\right.$ and $\left.2176 \mathrm{~cm}^{-1}\right)$ and $\mathrm{CO}_{2}\left(2360 \mathrm{~cm}^{-1}\right)$ were also evident and the intensity of their bands increased with time, which signifies that open compounds could be forming during the reaction.

\subsubsection{Reaction with $\mathrm{NO}_{3}$ radicals}

Analysis of GC-FID/MS chromatograms (see Fig. 3 in the Supplement) allowed the reaction products to be identified by their mass spectra and the retention times of authentic standards. The products were $(Z / E)$-2-methylbutenedial, 3-methyl-2,5-furanodione, 3-methyl-2(3H)-furanone and 5hydroxy-4-methyl-2(5H)-furanone. These compounds have also been identified as reaction products in the reactions of 3-methylfuran with $\mathrm{Cl}$ and $\mathrm{OH}$ radicals. The yields in $\% \mathrm{C}$ for the compounds identified were $0.45 \pm 0.07$ for 2-methylbutenedial, $0.36 \pm 0.07$ for 3-furaldehyde, $31.59 \pm 2.51$ for 3 -methyl-2,5-furandione and $1.97 \pm 0.25$ for 3-methyl-2(3H)-furanone.

It is known from the literature that nitrated compounds should be present as products from the reaction of 3methylfuran with $\mathrm{NO}_{3}$ radicals. However, due to the sampling method and analysis conditions (very high temperature in the injection port) these compounds were not identified by the SPME-GC/MS technique. As a result, different FTIR experiments were carried out in order to identify the nitrated compounds. The residual product FTIR spectrum from the oxidation of 3-methylfuran with $\mathrm{NO}_{3}$ radicals after subtraction of the spectra of 3-methylfuran, $\mathrm{N}_{2} \mathrm{O}_{5}, \mathrm{NO}_{2}$ and $\mathrm{HNO}_{3}$ is shown in Fig. 4c. Due to the lack of nitrated standards, the absorption bands were assigned to different compounds based on the IR spectrum analysis and the general tropospheric degradation mechanisms (Finlayson-Pitts and Pitts, 2000; Villanueva et al., 2007).

The most important spectral features are listed in Table 3 together with their assignments. Absorption bands at 792, 
Table 3. Infrared spectral features and their tentative assignment to the products of the reaction of 3-methylfuran $+\mathrm{NO}_{3}$.

\begin{tabular}{lllll}
$-\mathrm{ONO}_{2}\left(\mathrm{~cm}^{-1}\right)$ & $-\mathrm{OONO}_{2}\left(\mathrm{~cm}^{-1}\right)$ & $>\mathrm{CO}\left(\mathrm{cm}^{-1}\right)$ & $-\mathrm{CO}\left(\mathrm{cm}^{-1}\right)$ & $-\mathrm{OH}\left(\mathrm{cm}^{-1}\right)$ \\
\hline
\end{tabular}

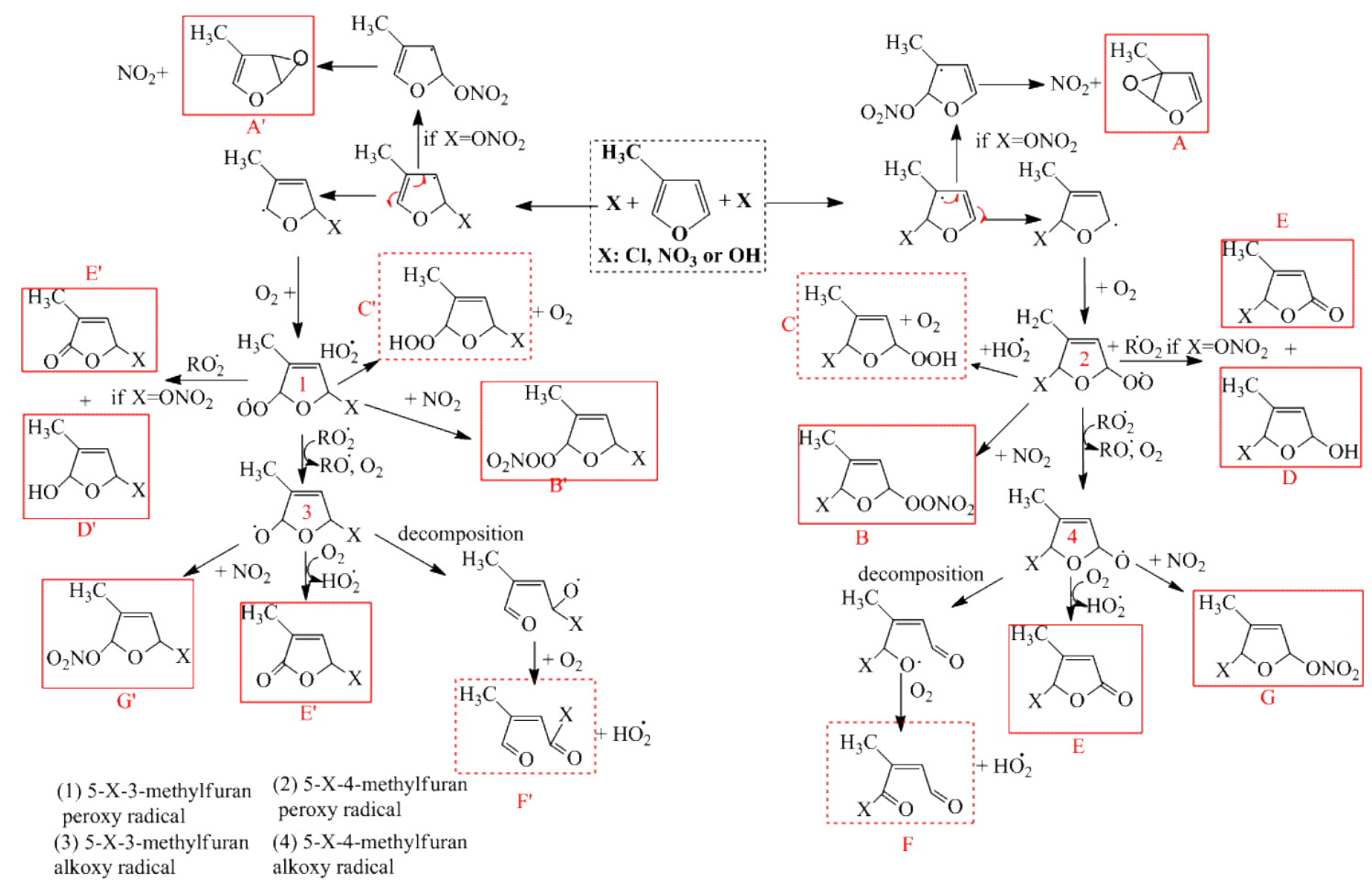

Scheme 1. Reaction sequences of 3-methylfuran and $X$ radical initiated by an addition process: possible mechanism for the formation of 5-X-3-methyl-2(5H)-furanone and 5-X-4-methyl-2(5H)-furanone. $\mathrm{X}$ : $\mathrm{Cl}, \mathrm{OH}$ or $\mathrm{NO}_{3}$. Compounds $\mathrm{C} / \mathrm{C}^{\prime}$ and $\mathrm{F} / \mathrm{F}^{\prime}$ were not detected.

1294 and $1732 \mathrm{~cm}^{-1}$ are attributable to nitroperoxy compounds $\left(-\mathrm{OONO}_{2}\right)$ based on the fact that nitroperoxy compounds decompose with time (Hjorth et al., 1990), a situation that was confirmed experimentally.
Absorption bands at $857,1287,1660$ and $1695 \mathrm{~cm}^{-1}$ are attributable to nitrooxy compounds $\left(-\mathrm{ONO}_{2}\right)$ considering that the typical bands of the $-\mathrm{ONO}_{2}$ group appear at 843 , 1296 and $1672 \mathrm{~cm}^{-1}$ (Tuazon et al., 1999). The presence of absorption bands at 1695 and $1660 \mathrm{~cm}^{-1}$ can be explained by 


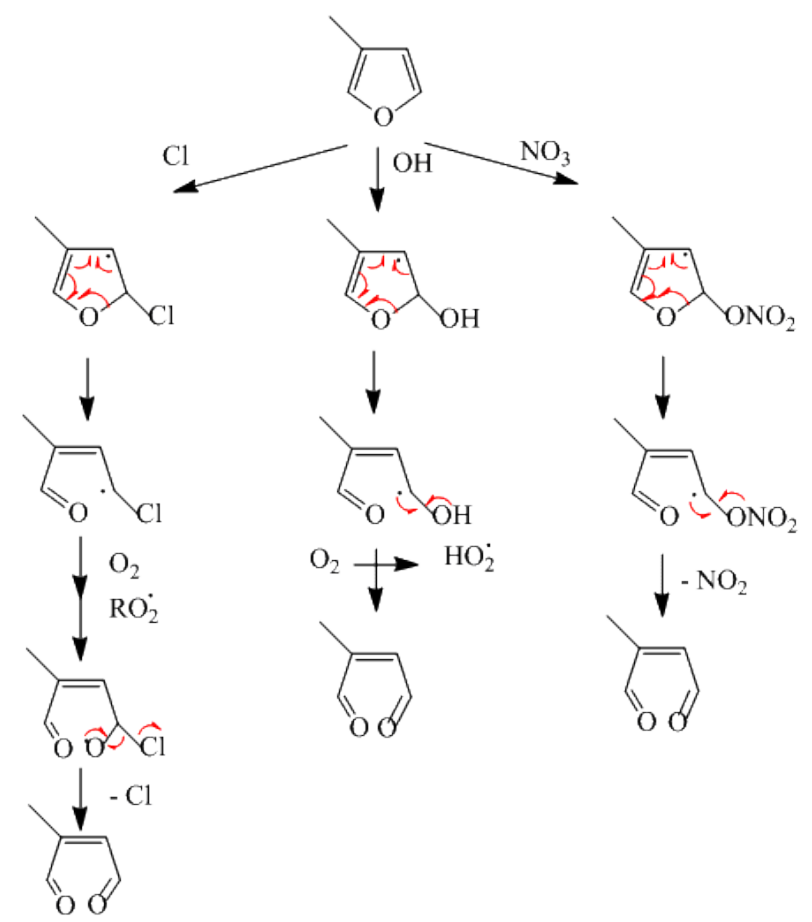

Scheme 2. Possible mechanisms for the formation of 2methylbutenedial in the reaction of 3-methylfuran with $\mathrm{Cl}, \mathrm{OH}$ and $\mathrm{NO}_{3}$.

the shift of the absorption band at $1672 \mathrm{~cm}^{-1}$, with the magnitude of the shift depending on the functional group around the $-\mathrm{ONO}_{2}$ group. Thus, the absorption band at $1695 \mathrm{~cm}^{-1}$ is attributed to a nitrooxy-hydroxyl compound and the band at $1660 \mathrm{~cm}^{-1}$ is attributed to a nitrooxy-carbonyl compound. The presence of absorption bands at $1000-1100 \mathrm{~cm}^{-1}$, which could be due to a $\mathrm{C}-\mathrm{O}$ stretch of an alcohol group or from the $\mathrm{C}-\mathrm{O}$ stretch of a nitrate group, is evident in Fig. 4c. In the FTIR spectra the region $3000-4000 \mathrm{~cm}^{-1}$ (O-H stretch) is characterised by a poor signal-to-noise ratio and it is, therefore, not possible to identify the compound(s) present. However, the general tropospheric degradation mechanism and different studies show that the formation of nitrooxyhydroxyl and nitrooxy-carbonyl is possible.

Absorption bands at $1829-1835 \mathrm{~cm}^{-1}$ are assigned to the carbonyl group of a lactone with an $-\mathrm{ONO}_{2}$ group in the $\beta$-position. The effect of the $-\mathrm{ONO}_{2}$ group on the carbonyl band in the lactone produces a similar displacement (to higher wavenumber) to that caused by $\mathrm{Cl}$ in chlorinated methylfuranones (Villanueva et al., 2007). Therefore, based on the results obtained with $\mathrm{Cl}$ and $\mathrm{OH}$, the band at $1829 \mathrm{~cm}^{-1}$ together with the bands at $857,1287,1660$ can be assigned to the isomers of nitrooxy-methyl-2(5H)-furanone.

The absorption band at $1021 \mathrm{~cm}^{-1}$ can also be assigned to a $\mathrm{C}-\mathrm{O}$ stretch of an alcohol group of the hydroxyfuranone compounds (a compound that was positively identified by GC-MS analysis), where the negative conjugative effect of the carbonyl group displaced the $\mathrm{C}-\mathrm{OH}$ band to lower wavenumber. The absorption band at $820 \mathrm{~cm}^{-1}$ and the bands at $3000 \mathrm{~cm}^{-1}$ are assigned to a reaction product with an epoxy group (Pounchert, 1989). These absorptions decreased markedly with time, indicating that the possible epoxy compound formed in the reaction is thermally unstable. Epoxy compounds have been observed in others studies into the $\mathrm{NO}_{3}$ radical (Wängberg et al., 1997; Martín et al., 2002). The simultaneous presence of these two sets of bands $\left(792,1294,1732\right.$ and 857, 1287, 1660, $\left.1695 \mathrm{~cm}^{-1}\right)$ also suggests the formation of $\mathrm{R}\left(\mathrm{ONO}_{2}\right)\left(\mathrm{OONO}_{2}\right)$-type compounds (Martín et al., 2002).

Evidence for compounds such as 3-furaldehyde, 3-methyl2,5-furanodione, 3-methyl-2(3H)-furanone and 5-hydroxy4-methyl-2(5H)-furanone was not found in the FTIR analysis, probably because the bands were overlapped by the bands of the major products (nitrate compounds).

\section{Reaction mechanism}

According to the reaction products identified in this work and based on literature data, it can be concluded that the main products for the reaction of 3-methylfuran with $\mathrm{OH}$ radicals, $\mathrm{NO}_{3}$ radicals and $\mathrm{Cl}$ atoms will come from the addition of the radical or atom to positions $\mathrm{C} 2$ or $\mathrm{C} 5$ because the most stabilized reaction intermediates are generated. H-atom abstraction is also likely to occur, but this will only be a minor process (Cabañas et al., 2005; Gu et al., 1995; Jones and Ham, 2008; Martín et al., 2002; Picquet-Varrault et al., 2002; Rollins et al., 2009, Skov et al., 1992; Smith et al., 1999; Villanueva et al., 2007, 2009; Wang et al., 2005; Zhou et al., 2006). Therefore, in Schemes 1 and 2 reaction mechanisms for the reaction of 3-methylfuran and $\mathrm{X}$ radicals $\left(\mathrm{OH}, \mathrm{NO}_{3}\right.$ or $\mathrm{Cl}$ ) are proposed in order to account for the formation of the main reaction products identified in this study.

The sequence is initiated by the addition of radical $\mathrm{X}$ to the carbon-carbon double bond at the 2- and/or 5-positions. In the case of the $\mathrm{NO}_{3}$ radical the resulting nitrooxyalkyl radicals can either decompose to form the epoxide (compounds $\mathrm{A}$ and/or $\mathrm{A}^{\prime}$ ) plus $\mathrm{NO}_{2}$ (this process typically decreases in importance as the total pressure and $\mathrm{O}_{2}$ content increases) or add $\mathrm{O}_{2}$ to form nitrooxyalkyl peroxy radicals $\left(5-\mathrm{ONO}_{2}-\right.$ 3-methylfuran peroxyradical or 5-ONO 2 -4-methylfuran peroxyradical) (Atkinson, 1991, 1997). The nitrooxyalkyl peroxy radicals can (a) react with $\mathrm{NO}_{2}$ to form thermally unstable peroxydinitrates $\left[\mathrm{R}\left(\mathrm{ONO}_{2}\right)\left(\mathrm{OONO}_{2}\right)\right.$ compounds $\mathrm{B}$ and/or $\mathrm{B}^{\prime}$ ], (b) react with $\mathrm{HO}_{2}$ radicals to form nitrooxy hydroperoxides (compounds $\mathrm{C}$ and/or $\mathrm{C}^{\prime}$ ) and (c) react with organic peroxy $\left(\mathrm{RO}_{2}\right)$ radicals. The reactions with organic peroxy radicals (including self-reaction) proceed (a) through a "molecular" channel, forming a nitrooxy alcohol and/or (if feasible) a nitrooxy carbonyl compound (compounds D and $\mathrm{E}$ and/or $\mathrm{D}^{\prime}$ and $\mathrm{E}^{\prime}$ ), and (b) through a "radical" channel to form the nitrooxy alkoxy radicals $\left(5-\mathrm{ONO}_{2}-3\right.$-methylfuran 
alkoxyradical or 5- $\mathrm{ONO}_{2}-4$-methylfuran alkoxyradical). The latter radicals are expected to (a) decompose to form dicarbonyl compounds as products (compounds $\mathrm{F}$ and/ or $\mathrm{F}^{\prime}$ ), (b) add $\mathrm{NO}_{2}$ to form dinitrate compounds $\left[\mathrm{R}\left(\mathrm{ONO}_{2}\right)\left(\mathrm{ONO}_{2}\right)\right.$ compounds $\mathrm{G}$ and/or $\mathrm{G}^{\prime}$ ] or (c) add molecular oxygen to form nitrooxycarbonyl compounds [compounds $\mathrm{E}$ and/or $\mathrm{E}^{\prime}$, 5-nitrooxy-2(5H)-methylfuranones] plus the $\mathrm{HO}_{2}$ radical. Our FT-IR results are consistent with this scheme, with evidence for the formation of the epoxide (bands $820 \mathrm{~cm}^{-1}$ and $3000 \mathrm{~cm}^{-1}$ compound $\mathrm{A}$ or $\mathrm{A}^{\prime}$ ), nitrooxy alcohol (compound $\mathrm{D}$ or $\mathrm{D}^{\prime}$ ) and nitrooxy carbonyl (compounds $\mathrm{E}$ or $\mathrm{E}^{\prime}$ ). The same sequence of reactions could be initiated by $\mathrm{OH}$ and $\mathrm{Cl}$ radicals and the products formed would be the same on changing $\mathrm{X}\left(\mathrm{ONO}_{2}\right)$ for $\mathrm{Cl}$ or $\mathrm{OH}$. Compounds $\mathrm{E}$ and $\mathrm{E}^{\prime}$ would, therefore, be 5-chloro-2-(5H)-methylfuranones for the reaction of 3-methylfuran with $\mathrm{Cl}$ atoms and 5-hydroxy$2(5 \mathrm{H})$-methylfuranones for the reaction with $\mathrm{OH}$ radicals. However, in the reaction with $\mathrm{Cl}$ atoms and $\mathrm{OH}$ radicals there was no evidence in the product analysis for the formation of compounds $\mathrm{D} / \mathrm{D}^{\prime}$, indicating that compounds $\mathrm{E}$ or $\mathrm{E}^{\prime}$ must be formed through a "radical" channel to yield alkoxy radicals.

2-Methylbutenedial is a primary product that arises from the addition of the oxidant to a double bond in the $\mathrm{C} 2$ or $\mathrm{C} 5$ position, with the intermediate undergoing ring opening and, depending on the nature of the substituent $\mathrm{X}\left(\mathrm{X}: \mathrm{OH}, \mathrm{NO}_{3}\right.$, $\mathrm{Cl}$ ), the process will be different (see Scheme 2). For the reaction with $\mathrm{OH}$, the $\mathrm{O}_{2}$ abstracts the $\mathrm{H}$-atom whereas in the case of $\mathrm{Cl}$ atoms and the $\mathrm{NO}_{3}$ radical the good characteristics of $\mathrm{Cl}$ and $\mathrm{NO}_{2}$ as leaving groups mean that these groups are eliminated. This mechanism was also proposed by Bierbach et al. (1995) and Berndt et al. (1997).

The yield of 3-methyl-2(3H)-furanone can be explained by intramolecular photoisomerization of 2-methylbutenedial in the presence of VIS and UV radiation (Scheme 1, Supplement) (Bierbach et al., 1994). In the case where $\mathrm{X}$ is $\mathrm{NO}_{3}$ there is no radiation but the presence of $\mathrm{HNO}_{3}$ probably stabilizes the zwitterionic intermediate and, thus, favours the process. 3-Methyl-2,5-furanodione can be formed by abstraction of the aldehydic hydrogen of 2-methylbutenedial with the radical X (Bierbach et al., 1994) (see Scheme 2 in the Supplement). In this case, 3-methyl-2,5-furanodione would be a secondary product and the yield of this, together with the yield of 3-methyl-2(3H)-furanone, would give the molar yield of 2-methylbutenedial. In the reaction of 3-methylfuran with $\mathrm{OH}$ radicals the yield of 3-methyl2,5-furanodione is high (18\%) and this indicates that 2methylbutenedial would be a main product.

The presence of 3-furaldehyde as a primary product can be explained by the attack of the radical $\mathrm{X}$ to 3-methylfuran with abstraction of an $\mathrm{H}$-atom from the methyl group to form a furfuryl radical, which evolves to form 3-furaldehyde (Scheme 3 in the Supplement). However, based on the yield obtained in this study (where the highest yield is about $7 \%$ for the $\mathrm{Cl}$ reaction) this process is not as favoured as the addition route.
Table 4. Atmospheric lifetimes for 3-methylfuran.

\begin{tabular}{lcc}
\hline Oxidant & $k / 10^{-10} \mathrm{~cm}^{3}$ molecule $\mathrm{e}^{-1} \mathrm{~s}^{-1}$ & $\tau$ \\
\hline $\mathrm{OH}$ & 1.13 & $2.5 \mathrm{~h}^{\mathrm{a}}$ \\
$\mathrm{NO}_{3}$ & 0.12 & $1 \mathrm{~h}^{\mathrm{b}}$ \\
$\mathrm{Cl}$ & 4.2 & 3 days $^{\mathrm{c}, \mathrm{d}}$ \\
$\mathrm{O}_{3}$ & $2.05 \times 10^{-7}$ & 1 day $^{\mathrm{e}, \mathrm{f}}$ \\
\hline
\end{tabular}

a,b Estimated on the basis of the average concentrations in the troposphere of $[\mathrm{OH}]=$ $1 \times 10^{6}$ radicals cm ${ }^{-3}$ (Prinn et al., 1992) and $\left[\mathrm{NO}_{3}\right]=2 \times 10^{7}$ radicals cm${ }^{-3}$ (Finlayson Pitts and Pitts, 2000), respectively. ${ }^{c, d}$ Estimated on the basis of kinetic rate coefficient for the reaction with $\mathrm{Cl}$ atoms at $298 \mathrm{~K}$ (Cabañas et al., 2005) and on the basis of the average concentrations in the troposphere of $[\mathrm{Cl}]=1 \times 10^{4}$ atoms $\mathrm{cm}^{-3}$ (Wingenter et al., 1996). e,f Estimated on the basis of a kinetic rate coefficient for the reaction with $\mathrm{O}_{3}$ molecules at $298 \mathrm{~K}$ (Alvarado et al., 1996) and on the basis of the average concentrations in the troposphere of $\left[\mathrm{O}_{3}\right]=7.4 \times 10^{11}$ molecule $\mathrm{cm}^{-3}$ (Logan, 1985).

The presence of 5-hydroxy-4-methyl-2(5H)-furanone and 5-hydroxy-3-methyl-2(5H)-furanone as products in the reaction of 3-methylfuran with $\mathrm{NO}_{3}$ and $\mathrm{Cl}$ was also confirmed. 5-Hydroxy-2(5H)-furanone was previously detected in the reaction of furan and alkylfurans with $\mathrm{Cl}$ atoms (Villanueva et al., 2007, 2009). In the case of furan, this compound was expected to be formed as a result of $\mathrm{H}$-abstraction from the aromatic ring. Similarly, in the reactions of 3methylfuran with $\mathrm{NO}_{3}$ radicals and $\mathrm{Cl}$ atoms, 5-hydroxy$2(5 \mathrm{H})$-methylfuranones can only be generated by $\mathrm{H}$-atom abstraction from the aromatic ring in positions $\mathrm{C} 2$ or C5 (see Scheme 4, Supplement). There are several reaction pathways for $\mathrm{RO}_{2}+\mathrm{RO}_{2}$ radical reactions and one involves the formation of an alcohol (R-OH) and a carbonyl (RCO) coproduct (as shown in Scheme 4, Supplement). In this particular reaction scheme, the carbonyl co-product formed is 3-methyl-2,5-furandione, which is observed experimentally. It was found in some studies that the abstraction of an $\mathrm{H}-$ atom from the aromatic ring in the reactions of p-xylene and 1,2,4-trimethylbenzene with $\mathrm{OH}$ is not favoured and the yields of the resulting methylquinones are low in comparison with those of products obtained in the addition processes (Smith et al., 1999). In the case of the reaction of 3-methylfuran with $\mathrm{NO}_{3}$ and $\mathrm{Cl}, 3$-methyl-2,5-furanodione is formed as a co-product and, therefore, in $\mathrm{Cl}$ reactions it is likely to provide a way to estimate the yield of the 5-hydroxy-2(5H)-methylfuranones. The yields of the 5hydroxy-2(5H)methylfuranones are, thus, expected to be $\leq$ $8 \%$.

In conclusion, the addition process with retention of configuration is the most important pathway for the reaction of 3 -methylfuran with $\mathrm{Cl}$ atoms. This fact is corroborated by the high yields of 5-chloro-2 $(5 H)$-methylfuranones. In the case of the reaction with $\mathrm{OH}$ the dominant reaction pathway is ring opening, although it is believed that 5-hydroxy-2(5H)methylfuranone (product with retention of configuration) is 
a significant product, although it could not be quantified. For the reaction with $\mathrm{NO}_{3}, 5$-nitrooxy-2 $(5 \mathrm{H})$-methylfuranones (products with retention of configuration) were not identified by GC/MS and they were only tentatively assigned to certain bands in the IR spectrum. The formation of these compounds is probably consistent with the results obtained in the $\mathrm{OH}$ and $\mathrm{Cl}$ reactions. In addition, due to the low yield obtained for 2methylbutenedial it is not possible to determine the dominant reaction pathway.

It is important to note that the degradation mechanism of 3-methylfuran with $\mathrm{Cl}$ atoms is the same as that proposed for furan with $\mathrm{Cl}$ atoms. Indeed, this process will yield the same products as obtained from furan, but with the corresponding methyl group (Villanueva et al., 2007).

\section{Atmospheric implications}

The kinetic data obtained in this study can be used to calculate atmospheric lifetimes for 3-methylfuran due to reaction with the oxidants $\mathrm{OH}, \mathrm{NO}_{3}, \mathrm{Cl}$ and $\mathrm{O}_{3}$ by applying Eq. (4)

$\tau_{\text {total }}=\frac{1}{k_{\mathrm{X}}[\mathrm{X}]}$

The average $(24 \mathrm{~h})$ concentrations of these compounds in the troposphere are as follows: $[\mathrm{OH}]=$ $1 \times 10^{6}$ radicals cm ${ }^{-3}$ (Prinn et al., 1992), $\left[\mathrm{NO}_{3}\right]=2 \times 10^{7}$ radicals $\mathrm{cm}^{-3}$ (Finlayson-Pitts and Pitts, 2000), $\left[\mathrm{O}_{3}\right]=$ $7.4 \times 10^{11}$ molecule $\mathrm{cm}^{-3}$ (Logan, 1985), and $[\mathrm{Cl}]=$ $1 \times 10^{4}$ atoms cm$~^{-3}$ (Wingenter et al., 1996) assuming an average concentration of chlorine atoms in the global marine boundary layer. As shown in Table $4, \mathrm{OH}$ and $\mathrm{NO}_{3}$ radicals are globally the most important sinks for 3-methylfuran at daytime and nighttime, respectively, with lifetime values of 2.5 and $1 \mathrm{~h}$, but chlorine will compete with these oxidants as a sink in coastal urban areas where its concentration increases at dawn (Spicer et al., 1998). The lifetimes given in Table 4 provide only an approximate estimate of the global mean lifetime because the use of average radical concentrations is really not appropriate for such a short lived species.

In order to evaluate the atmospheric importance of a particular reaction, it is necessary to consider the reaction mechanism and the product formation. The results of this work are consistent with the remarks and conclusions outlined below.

As explained in our previous publication (Villanueva et al., 2009), certain chlorinated compounds, such as the chlorinated-methylfuranones determined in this work, are formed in the atmosphere by the reaction of $\mathrm{Cl}$ atoms with the parent VOC. Therefore, if a chlorinated product can be identified from a particular reaction involving $\mathrm{Cl}$, these products could serve as "markers" in the chemistry of $\mathrm{Cl}$ atoms in the troposphere.

On the other hand, the majority of compounds identified from the reaction of 3-methylfuran with $\mathrm{NO}_{3}$ are nitrated compounds. These compounds can act as $\mathrm{NO}_{\mathrm{x}}$ reservoir species (or sinks), especially during the night.

In recent years, the California Air Resources Board (CARB) has adopted regulations for volatile organic compounds (VOCs) based on calculations of their relative ground-level ozone impacts. For the purposes of these regulations, the impact levels are quantified using the Maximum Incremental Reactivity (MIR) scale. This scale was developed by Carter (1994) and is based on model calculations for the effects of additions of VOCs on ozone formation in oneday box model scenarios that represent conditions where ambient ozone is most sensitive to changes in VOC emissions.

These calculations require a model or models for airshed conditions, a method for quantifying ozone impacts, and a chemical mechanism to calculate the effects of the reactions of VOCs on ozone formation in the atmosphere. In the last calculation of MIR values, 3-methylfuran was included and its value is $6.9 \mathrm{~g}_{3} / g_{\mathrm{VOC}}$ (Carter, 2010). This value indicates that 3-methylfuran is a potential source of ozone generation to a greater extent than other compounds that are more abundant in the atmosphere - due to its high atmospheric reactivity with the main atmospheric oxidants.

\section{Supplementary material related to this article is available online at: http://www.atmos-chem-phys.net/11/3227/2011/ acp-11-3227-2011-supplement.zip.}

Acknowledgements. Florentina Villanueva García thanks the "Junta de Comunidades de Castilla La Mancha" for a personal grant. Araceli Tapia Valle thanks the Spanish Ministerio de Educación y Ciencia for the personal grant BES-2005-6830. This work was supported by Projects PAI06-0042 granted by the JCCM ("Junta de Comunidades de Castilla La Mancha") and CGL2004-03355/CLI and ENE2004-07776-C03-03 granted by Spanish Ministerio de Ciencia y Tecnologia (MCyT). The assistance and very helpful suggestions from Ian Barnes and Iustinian Bejan are gratefully acknowledged.

Edited by: J. B. Burkholder

\section{References}

Alvarado, A., Atkinson, R., and Arey, J.: Kinetics of the gas-phase reactions of $\mathrm{NO}_{3}$ radicals and $\mathrm{O}_{3}$ with 3-methylfuran and the $\mathrm{OH}$ radical yield from the $\mathrm{O}_{3}$ reaction, Int. J. Chem. Kinet., 28(12), 905-909, 1996.

Andreae, M. O. and Merlet, P.: Emission of trace gases and aerosols from biomass burning, Global Biogeochem. Cy., 15(4), 955-966, 2001.

Aschmann, S. M. and Atkinson, R.: Rate constants for the gasphase reactions of alkanes with $\mathrm{Cl}$ atoms at $296 \pm 2 \mathrm{~K}$, Int. J. Chem. Kinet., 27(6), 613-622, 1995.

Atkinson, R.: Kinetics and mechanisms of the gas-phase reactions of the $\mathrm{NO}_{3}$ radical with organic compounds, J. Phys. Chem. Ref. Data, 20, 459-507, 1991. 
Atkinson, R.: Gas-Phase Tropospheric Chemistry of Volatile Organic Compounds: Alkanes and Alkenes, J. Phys. Chem. Ref. Data, 26, 215-290, 1997.

Atkinson, R., Aschmann, S. M., Carter, W. P. L., Winer, A. M., and Pitts, J. N. Jr.: Kinetics of the reactions of OH radicals with n-alkanes at 299 $\pm 2 \mathrm{~K}$, Int. J. Chem. Kinet., 14, 781-788, 1982.

Atkinson, R., Plum, C. N., Carter, W. P. L., Winer, A. M., and Pitts Jr., J. N.: Rate Constants for the Gas Phase Reactions of $\mathrm{NO}_{3}$ Radicals with a Series of Organics in Air at $298 \pm 1$ K, J. Phys. Chem., 88, 1210-1215, 1984.

Atkinson, R., Aschmann, S. A., Tuazon, E. C., Arey, J., and Zielinska, B.: Formation of 3-Methylfuran from the Gas-Phase Reaction of $\mathrm{OH}$ Radicals with Isoprene and the Rate Constant for its Reaction with the OH Radical, Int. J. Chem. Kinet., 21, 593-604, 1989.

Barnes, I., Becker, K. H., and Mihalopoulos, N.: An FTIR products study of the photooxidation of dimethyl disulfide, J. Atmos. Chem., 18, 267-289, 1994.

Berndt, T., Böge, O., and Rolle, W.: Products of the gas-phase reactions of $\mathrm{NO}_{3}$ radicals with furan and tetramethylfuran, Environ. Sci. Technol., 31, 1157-1162, 1997.

Bierbach, A., Barnes, I., Becker, K. H., and Wiesen, E.: Atmospheric chemistry of usaturated carbonyls: butenedial, 4-oxo2-pentenal, 3-hexene-2,5-dione, maleic anhydride, 3H-furan-2one, and 5-methyl-3H-furan-2-one, Environ. Sci. Technol., 28, 715-729, 1994.

Bierbach, A., Barnes, I., and Becker, K. H.: Product and kinetic study of the $\mathrm{OH}$-initiated gas-phase oxidation of furan, 2methylfuran and furanaldehydes at $300 \mathrm{~K}$, Atmos. Environ., 29 (19), 2651-2660, 1995.

Cabañas, B., Villanueva, F., Martín, P., Baeza, M. T., Salgado, S., and Jiménez, E.: Study of reaction processes of furan and some furan derivatives initiated by $\mathrm{Cl}$ atoms, Atmos. Environ., 39, 1935-1944, 2005.

Cabañas, B., Tapia, A., Villanueva, F., Salgado, S., Monedero, E., and Martín, P.: Kinetic study of 2-furanaldehyde, 3furanaldehyde and 5-methyl-2-furanaldehyde reactions initiated by $\mathrm{Cl}$ atoms, Int. J. Chem. Kinet., 40(10), 670-678, 2008.

Carter, W. P. L.: Development of ozone reactivity scales for volatile organic compounds, J. Air Waste Manage., 44, 881-899, 1994.

Carter, W. P. L.: Development of the SAPRC-07 Chemical Mechanism and Updated Ozone Reactivity Scales. Final report to the California Air Resources, available at: www.cert.ucr.edu/ $\sim$ carter/SAPRC, 2010.

Edney, E. O., Kleindienst, T. E., and Corse, E. W.: Room temperature rate constants for the reaction of $\mathrm{OH}$ with selected chlorinated and oxygenated hydrocarbons, Int. J. Chem. Kinet., 18, 1355-1371, 1986.

Finlayson-Pitts, B. J. and Pitts, J. N.: Chemistry of the upper and lower atmosphere: Theory, Experiments and Applications, San Diego, Academic Press, 2000.

Gómez Álvarez, E., Borrás, E., Viidanoja, J., and Hjorth, J.: Unsaturated dicarbonyl products from the OH-initiated Photooxidation of furan, 2-methylfuran and 3-methylfuran, Atmos. Environ., 43, 1603-1612, 2009.

Graedel, T. E., Hawkings, D. T., and Claxton, L. D.: Atmospheric chemical compounds: Sources Occurrence, and Bioassay, Academic press, New York, 1986.

Gu, C. L., Rynard C. M., Hendry, D. G., and Mill, T.: Hydroxyl
Radical Oxidation of Isoprene, Environ. Sci. Technol., 29, 24672469, 1995.

Guenther, A., Karl, T., Harley, P., Wiedinmyer, C., Palmer, P. I., and Geron, C.: Estimates of global terrestrial isoprene emissions using MEGAN (Model of Emissions of Gases and Aerosols from Nature), Atmos. Chem. Phys., 6, 3181-3210, doi:10.5194/acp-63181-2006, 2006.

Hjorth, J., Lobse, C., Nielsen, C. J., Skov, H., and Restelli, G.: Products and mechanisms of the gas-phase reactions between $\mathrm{NO}_{3}$ and a series of alkenes, J. Phys. Chem., 94, 7494-7500, 1990.

Jones, B. T. and Ham, J. E.: $\alpha$-Terpineol reactions with the nitrate radical: Rate constant and gas-phase products, Atmos. Environ., 42, 6689-6698, 2008.

Kind, I., Berndt, T., Boge, O., and Rolle, W.: Gas-phase rate constants for the reaction of $\mathrm{NO}_{3}$ radicals with furan and methylsubstituted furans, Chem. Phys. Lett., 256, 679-683, 1996.

Kumar, P. and Pandey, R. K.: An efficient synthesis of 5-hydorxy2(5H)-furanone, Green Chem., 2(1), 29-32, 2000.

Laothawornkitkul, J., Taylor, J. E., Paul, N. D., and Hewitt, C. N.: Biogenic volatile organic compounds in the Earth system, New Phytol., 183, 27-51, 2009.

Lee, W., Baasandorj, M., Stevens, P. S., and Hites, R. A.: Monitoring OH-Initiated Oxidation Kinetics of Isoprene and Its Products. Products Using Online Mass Spectrometry, J. Phys. Chem. A, 109(21), 4728-4735, 2005.

Logan, J. A.: Tropospheric ozone-seasonal behaviour, trends, and anthropogenic influence, J. Geophys. Res., 90, 463-482, 1985.

Martín, M. P., Tuazon, E. C., Aschmann, S. M., Arey, J., and Atkinson, R.: Formation and atmospheric reactions of 4,5-dihydro-2methylfuran, J. Phys. Chem. A, 106, 11492-11501, 2002.

Martínez, E., Cabañas, B., Aranda, A., and Martín, P.: Kinetics of the reactions of $\mathrm{NO}_{3}$ radical with selected monoterpenes: a temperature dependence study, Environ. Sci. Technol., 32(23), 3730-3734, 1998.

Montzka, S. A., Trainer, M., Angevine, W. M., and Fehsenfeld, F. C.: Measurements of 3-methyl furan, methyl vinyl ketone, and methacrolein at a rural forested site in the southeastern United States, J. Geophys. Res., 100(D6), 11393-11401, 1995.

Nielsen, O. J., Jorgensen, O., Donlon, M., Sidebottom, H. W., O'Farrell, D. J., and Treacy, J.: Rate constants for the gas-phase reactions of $\mathrm{OH}$ radicals with nitroethene, 3-nitropropene and 1nitrocyclohexene at $298 \mathrm{~K}$ and $1 \mathrm{~atm}$, Chem. Phys. Lett., 168, 319-323, 1990.

Picquet-Varrault, B., Doussin, J. F., Durrand-Jolibois, R., Pirali, O., and Carlier, P.: Kinetic and mechanistic study of the atmospheric oxidation by $\mathrm{OH}$ radicals of allyl acetate, Environ. Sci. Technol., 36, 4081-4086, 2002.

Pounchert, C. J.: The Aldrich Library of FT-IR spectra, Aldrich Company Inc., Catalog number: z-18400-4, Volume 3, Edition I, 1989.

Prinn, R., Cunnold, D., Simmonds, P., Alyea, F., Boldi, R., Crawford, A., Froser, P., Gutzler, D., Hartley, R., Rosen, R., and Rasmussen, R.: Gloval average concentration and trend for hydroxyl radicals deduced from ALE/GAGE trichloroethane (methylchloroform) data for 1978-1990, J. Geophys. Res., 97, 2445-2461, 1992.

Rollins, A. W., Kiendler-Scharr, A., Fry, J. L., Brauers, T., Brown, S. S., Dorn, H.-P., Dubé, W. P., Fuchs, H., Mensah, A., Mentel, T. F., Rohrer, F., Tillmann, R., Wegener, R., Wooldridge, P. J., and 
Cohen, R. C.: Isoprene oxidation by nitrate radical: alkyl nitrate and secondary organic aerosol yields, Atmos. Chem. Phys., 9, 6685-6703, doi:10.5194/acp-9-6685-2009, 2009.

Ruppert, L. and Becker, K. H.: A product study of the OH radicalinitiated oxidation of isoprene: formation of C5-unsaturated diols, Atmos. Environ., 34(10), 1529-1542, 2000.

Scalon, T. J. and Willis, D. E.: Calculation of flame ionization detector response factors using effective number concept, J. Chromatogr. Sci., 23, 333-340, 1985.

Skov, H., Hjorth, J., Lohse, C., Jensen, N. R., and Restelli, G.: Products and mechanisms of the reactions of the nitrate radical $\left(\mathrm{NO}_{3}\right)$ with isoprene, 1,3-butadiene and 2,3-dimethyl-1,3-butadiene in air, Atmos. Environ., 26A(15), 2771-2783, 1992.

Smith, D. F., Kleindienst, T. E., and McIver, C. D.: Primary product distributions from the reaction of $\mathrm{OH}$ with $\mathrm{m}$-, p-xylene, 1,2,3- and 1,3,5-trimethylbenzene, J. Atmos. Chem., 34, 339364, 1999.

Spicer, C. W., Champman, E. G., Finlayson-Pitts, B. J., Plastidge, R. A., Hubbe, J. M., Fast, J. D., and Berkowitz, C. M.: Observations of molecular chlorine in coastal air, Nature, 394(6691), 353-356, 1998.

Tang, Y. and Zhu, L.: Photolysis of butenedial at 193, 248, 280, 308, 351, 400, and $450 \mathrm{~nm}$, Chem. Phys. Lett., 409, 151-156, 2005.

Tuazon, E. C., Mac Leod, H., Atkinson, R., and Carter, W. P. L.: $\alpha$ Dicarbonyl yields fron the NOx-air photooxidations of a series of aromatic hydrocarbons in air, Environ. Sci. Technol., 20, 383387, 1986.

Tuazon, E. C., Alvarado, A., Aschmann, S., Atkinson, R., and Arey, J.: Products of the gas-phase reactions of 1,3-butadiene with $\mathrm{OH}$ and $\mathrm{NO}_{3}$ radicals, Environ. Sci. Technol., 33, 3586-3595, 1999.
Villanueva, F., Barnes, I., Monedero, E., Salgado, S., Gómez, M. V., and Martín, P.: Primary product distribution from the Cl-atom initiated atmospheric degradation of furan: Environmental implications, Atmos. Environ., 41(38), 8796-8810, 2007.

Villanueva, F., Cabañas, B., Monedero, E., Salgado, S., Bejan, I., and Martín, P.: Atmospheric degradation of alkylfurans with chlorine atoms: product and mechanistic study, Atmos. Environ., 43(17), 2804-2813, 2009.

Wang, L., Arey, J., and Atkinson, R.: Reactions of chlorine atoms with a series of aromatic hydrocarbons, Environ. Sci. Technol., 39, 5302-5310, 2005.

Wängberg, I., Barnes, I., and Becker, K. H.: Product and Mechanistic Study of the Reaction of $\mathrm{NO}_{3}$ Radicals with $\alpha$-Pinene, Environ. Sci. Technol., 31, 2130-2135, 1997.

Wingenter, O. W., Kubo, M. K., Blake, N. J., Smith Jr., T. W., Blake, D. R., and Rowland, F. S.: Hydrocarbon and halocarbon measurements as photochemical and dynamical indicators of atmospheric hydroxyl, atomic chlorine, and vertical mixing obtained during Lagrangian flights, J. Geophys. Res., 101, 4331-4340, 1996.

Zhang, W., Du, B., Mu, L., and Feng, C.: Mechanism for the gasphase reaction between $\mathrm{OH}$ and 3-methylfuran: Mechanism for the gas-phase reaction between $\mathrm{OH}$ and 3-methylfuran: A theoretical study, Int. J. Quant. Chem., 108, 1232-1238, 2008.

Zhou, S., Barnes, I., Zhu, T., Bejan, I., and Benter, T.: Kinetic study of the gas-phase reactions of $\mathrm{OH}$ and $\mathrm{NO}_{3}$ radicals and $\mathrm{O}_{3}$ with selected vinyl ethers, J. Phys. Chem. A, 110(23), 7386-7392, 2006. 